Anaerobes in the microbiome

\title{
Anaerobic biodegradation of fluoxetine using a high-performance bacterial community
}

\author{
Tânia Luz Palma a, b, Maria Clara Costa ${ }^{\text {a, b, * }}$ \\ ${ }^{a}$ Centro de Ciências do Mar, University of Algarve, Campus de Gambelas, Building 7, 8005-139, Faro, Portugal \\ ${ }^{\mathrm{b}}$ Faculdade de Ciencias e Tecnologias, University of Algarve, Campus de Gambelas, Building 8, 8005-139, Faro, Portugal
}

\section{A R T I C L E I N F O}

\section{Article history:}

Received June 2020

Received in revised form

11 February 2021

Accepted 6 March 2021

Available online 22 March 2021

Handling Editor: Kornél L. Kovács

\section{Keywords:}

Fluoxetine

Anaerobic community

Sulphate-reducing bacteria community

Biodegradation

\begin{abstract}
A B S T R A C T
Fluoxetine (FLX), an antidepressant extensively used worldwide is considered an emerging pollutant. The present work intends to investigate for the first time the capacity of a bacterial community containing sulphate-reducing bacteria (SRB) enriched from an anaerobic sludge to biodegrade and use FLX as sole carbon source, since current literature suggests that this drug is poorly biodegraded being mainly removed by adsorption to sediments, where it persists. FLX was biodegraded under sulphate reducing conditions until reaching its lowest and reliably detectable concentration, when $20 \mathrm{mg} / \mathrm{L}$ of the drug was used as sole carbon source, while $66 \pm 9 \%$ of $50 \mathrm{mg} / \mathrm{L}$ FLX was removed, after 31 days. The initial bacterial population was mainly constituted by Desulfomicrobium and Desulfovibrio whereas during the experiments using FLX as unique carbon source a clear shift occurred with the increase of vadinBC27 wastewater-sludge group, Macellibacteroidetes, Dethiosulfovibrio, Bacteroides, Tolumonas, Sulfuricurvum, f_Enterobacteriaceae_OTU_18 that are assumed for the first time as FLX degrading bacteria. Although the main mechanism of FLX removal described in literature is by adsorption, in the results herein presented anaerobic biodegradation appears to play the main role in the removal of the FLX, thus demonstrating the potentialities that the anaerobic processes can play in wastewater treatment aiming the removal of new emerging compounds.
\end{abstract}

() 2021 Elsevier Ltd. All rights reserved.

\section{Introduction}

Fluoxetine (FLX) or (R,S)-N-methyl-3-phenyl-3-(4-(trifluoromethyl)phenoxy)propan-1-amine (CAS No: [54910-89-3]) is among the widely used pharmaceutical drugs considered as emerging pollutants [1-3]. FLX is a selective serotonin reuptake inhibitor (SSRI) which is indicated mainly for treatment of depression, panic, anxiety, or obsessive-compulsive symptoms and is one of the most prescribed drugs worldwide. FLX (Fig. 1a) is mainly metabolized by humans to norfluoxetine (NFLX) (Fig. 1b) through O-dealkylation releasing $p$-trifluoromethylphenol, which is further metabolized to hippuric acid $\left(\mathrm{C}_{9} \mathrm{H}_{9} \mathrm{NO}_{3}\right)$ [4,5].

The biodegradation behaviour and sorption onto a matrix of a compound, herein FLX and NFLX, can be predicted by a group of important physico-chemical properties which are shown in Table 1 [8-10].

For example, Gros and colleagues [11] concluded that biodegradable substances exhibit a high pseudo-first order degradation constant $\left(\mathrm{K}_{\text {biol }}\right)$ or low half-life $\left(\mathrm{t}_{1 / 2}\right)$, having a low sludgewater distribution coefficient or sorption coefficient ( $\log K_{d}$ ), corresponding to the minimal tendency to adsorb on sewage sludge. Thus, it is normally predictable that compounds with low water solubilities, higher $\log \mathrm{K}_{\mathrm{ow}}(>2.5)$ and higher $\log \mathrm{K}_{\mathrm{d}}$ would be likely removed and subsequently found in organic-rich biosolids as described by Velázquez and Nacheva [9]. In the case of FLX, it is predictable a roughly biodegradation and a good sorption profile, since values of $K_{\text {biol }}$ were ranging from 0.03 to 9.0, thus displaying a poor to considerable biodegradability which likely may depend on the operational conditions. The drug displayed values of $\log K_{d}$ ranging from 2.76 to $3.78\left(\log K_{d}>2.7\right)$ that are characteristic of a high adsorption potential and also FLX is on the border of behaving like a lipophilic compound with a Log $\mathrm{K}_{\text {ow }}$ higher than 4 [8-10].

Environmental contamination with this drug and its active metabolite NFLX has been detected in sewage effluents and in

\footnotetext{
* Corresponding author. Centro de Ciências do Mar, University of Algarve, Campus de Gambelas, Building 7, 8005-139, Faro, Portugal.

E-mail addresses: tcpalma@ualg.pt (T.L. Palma), mcorada@ualg.pt (M.C. Costa).
} 
a

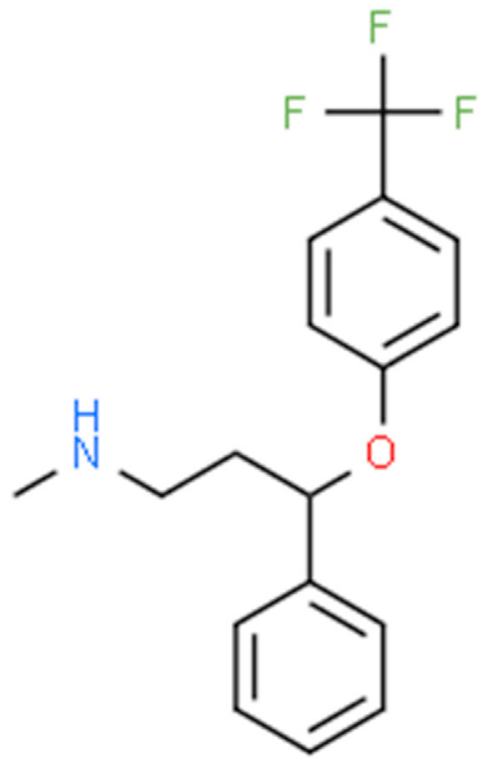

b

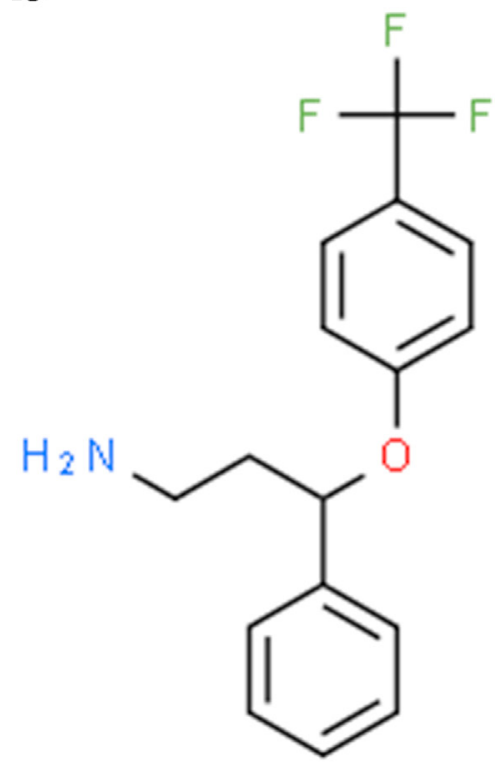

Fig. 1. Molecular structure of FLX (a) and NFLX (b) (ChemSpider database 2019) [6,7].

Table 1

Physico-chemical properties of FLX and NFLX.

\begin{tabular}{|c|c|c|c|}
\hline \multirow[t]{2}{*}{ Properties } & \multicolumn{2}{|l|}{ Drug } & \multirow[t]{2}{*}{ References } \\
\hline & FLX (CAS \# 54910-89-3) & NFLX & \\
\hline Solubility in water & $0.0017 \mathrm{mg} / \mathrm{mL}$ & $0.00915 \mathrm{mg} / \mathrm{mL}$ & Wishart et al. [8] \\
\hline Dissociation constant (pKa) & $9.8-10.3$ & 9.77 & Velázquez and Nacheva [9] \\
\hline $\log K_{d}$ (solid-water & $2.76 ; 3.76-3.78$ & Not available & Velázquez and Nacheva [9] \\
\hline $\begin{array}{l}\text { distribution coefficient) } \\
\mathrm{K}_{\text {biol }}\left(\mathrm{L} \mathrm{gVSS}^{-1} \mathrm{~d}^{-1}\right)\end{array}$ & $0.03-0.244$ and $0.6-9.0$ & Not available & Velázquez and Nacheva [9] \\
\hline Log $K_{\text {ow (octanol-water partition coefficient) }}$ & 4.05 & 4.17 & Velázquez and Nacheva; Das et al. $[9,10]$ \\
\hline $\log \mathrm{D}_{\text {lipw }}(\mathrm{pH} 7)$ & 3.28 & Not available & Velázquez and Nacheva [9] \\
\hline Charge at $\mathrm{pH} 7$ & Positive & Not available & Wishart et al. [8] \\
\hline
\end{tabular}

surface waters [12,13].

For example, The Predicted Environmental Concentrations (PEC) of $(\mathrm{R}, \mathrm{S})$-FLX in raw wastewater in Spain have been determined to be in the range from 80 to $200 \mathrm{ng} / \mathrm{L}$ [14]. FLX and NFLX were found in United Kingdom's wastewater influents in the range of 4.9-175.9 $\mathrm{ng} / \mathrm{L}$ and 3.4-118 $\mathrm{ng} / \mathrm{L}$, respectively and in the effluents were detected ranging from 5.6-44.9 ng/L FLX and 1.1-20.2 ng/L NFLX [15]. In Portugal, FLX was only detected in the influent wastewaters, with a frequency of $5 \%$, in a mean detected concentration of $127.97 \mathrm{ng} / \mathrm{L}$ (14.6 mg/day/1000 inhab.) [16]. Benotti et al. [17] found that United States of America tap water was contaminated with $0.64 \mathrm{ng} / \mathrm{L}$ FLX and $0.77 \mathrm{ng} / \mathrm{L}$ NFLX. Furthermore, fish collected near the municipal wastewater discharges were contaminated with these compounds [5]. Thus, municipal effluents with an upstream dilution present an important benefit to the aquatic environments reducing the maximal risk of contamination $[18,19]$. Although the drug concentrations detected are not acutely toxic to aquatic organisms [18], both FLX and NFLX remain biochemically active in the aquatic environments and may cause remarkable harmful effects on the morphology, physiology, behaviour, reproduction of different organisms and immunotoxic effects, since these compounds frequently act by mimicking the neurotransmitter serotonin [5,18-23]. Kwon and Armbrust [24] reported that FLX did not suffer hydrolysis, photolysis and microbial degradation and the main mechanism of removal was by adsorption to sediments. These authors detected NFLX as the unique metabolite of FLX, produced by demethylation, during the photolysis in a sample of synthetic humic water [24]. Also, Kinney et al. [25] reported adsorption of FLX to biosolids produced by wastewater treatment plant. Cartwright et al. [26] reported that the removal efficiency of FLX in an activated sludge treatment was over $90 \%$, but it was adsorbed by sludge and not biodegraded. Also, Moreira et al. [27] investigated FLX adsorption to aerobic microbial granules in an aerobic granular sludge (AGS) sequential batch reactor and proposed the development of adsorption/desorption mechanisms to remove this pharmaceutical from wastewater. The literature suggested adsorption as main mechanism of FLX removal. However, in some studies such as for example the one of Moreira et al. [28] demonstrated that Labrys portucalensis strain F1 completely removed $2 \mu \mathrm{M}$ of FLX in 30 days and Velázquez and Nacheva [9] reported that an ammonium-nitrite-oxidizing consortium was able to biodegrade $79 \%$ of the drug, while a heterotrophic consortium displayed the highest fluoxetine removal of $85 \%$.

Nevertheless, all the effects caused by FLX and NFLX in the environment are still unknown and the studies are scarce [24,29-31]. Hence the need to investigate for new, effective, lowcost, and ecological ways to degrade or remove these pharmaceuticals from wastewater.

Microorganisms, specifically bacteria have already 
demonstrated to play a vital role on the biodegradation of organic compounds [32]. The present study focuses on the search for anaerobic bacterial communities with capacity to biodegrade FLX, considering the recognized advantages of consortia over pure cultures [33].

Other aspect that must be considered is that the anaerobic processes are regarded by several authors as an environmentally and energetic sustainable technology when compared with the aerobic processes [34-37]. Anaerobic processes are normally implemented for streams with high concentrations of organic material, often prior to an aerobic treatment and are also used for specific applications, such as treatment of waste streams with recalcitrant pollutants (e.g. inorganics and/or chlorinated hazardous compounds). These processes are also well-adapted for treating industrial wastewater [37]. These anaerobic technologies are not duly explored; thus, this work aimed to search and evaluate the behaviour of an obtained SRB community that displayed the ability to degrade FLX, which is a recalcitrant compound with a strong and extremely difficult to break C-F bond. Poh et al. [36] claimed that the application of an appropriate model and process control can maximize the anaerobic process efficiency, improve sustainability of plant operation, and stimulate more groups to adopt anaerobic wastewater treatment systems, leading to a reduction in greenhouse gas emissions.

For that purpose, a sludge collected in an anaerobic lagoon system was enriched to favour the growth of a SRB community. The selection of SRB bacteria was driven by the following reasons: the SRB bacteria are ubiquitous in the environment, they are easy to grow and maintain. In addition, our research group has a wide research experience with SRB communities and have successfully using them in several bioremediation studies almost all exclusively related with acid mine drainage remediation [38-41]. Therefore, it was intended to investigate eventual additional bioremediation capacities of SRB consortia that were never explored. The experiments were performed in cultures using a modified Postgate B medium, a specific medium to favour SRB growth, in the presence of lactate plus FLX or only with the drug as possible carbon source, under sulphate reduction conditions. A mineral salt medium (MSM), a non-specific medium was also used to test the biodegradation and use of FLX as unique carbon source by other bacteria than SRB that were present in the community, under anaerobic conditions. A metagenomic analysis of the 16S rRNA gene sequences was performed aiming the bacterial identification in order to investigate which members from this anaerobic community may be responsible for FLX biodegradation, as well as to follow the bacterial community evolution during the experiment.

\section{Materials and methods}

\subsection{Inoculum sources and preparation}

A SRB consortium was enriched from an anaerobic sludge collected from Faro East WWTP's lagoon system (anaerobic pond) in a Postgate B medium (sulphate reduction conditions) and was used as inoculum to test the ability of that community in FLX degradation under anaerobic conditions. The enrichments were realized under anaerobic conditions at room temperature $\left(25 \pm 2{ }^{\circ} \mathrm{C}\right)$ in the dark. All the assays were performed using $10 \%(\mathrm{v} /$ v) of inoculum in batch using serum bottles of $100 \mathrm{~mL}$ without stirring. The $\mathrm{pH}$ of culture media was adjusted to 7 with $5 \mathrm{M} \mathrm{NaOH}$.

The initial enrichments were performed without the drug and in the presence of 5, 10 and $20 \mathrm{mg} / \mathrm{L}$ of FLX (Fig. 2). The bacteria were harvested in the exponential phase (corresponding to a bacterial growth ranging from 0.5 to 0.7 ) depending on the decrease in sulphate concentration from about $2000 \mathrm{mg} / \mathrm{L}$ to $400 \mathrm{mg} / \mathrm{L}$, considering that a sulphate concentration below this last concentration appears to be limiting for bacterial growth. The enrichment stabilization was considered when, after 3 re-inoculations, the obtained cultures followed a pattern of an optical density at $600 \mathrm{~nm}$ $\left(\mathrm{OD}_{600 \mathrm{~nm}}\right)$ ranging from 0.5 to 0.6 , a redox potential of approximately $-400 \mathrm{mV}$ and sulphate concentrations up to $400 \mathrm{mg} / \mathrm{L}$, between 7 and 14 days of inoculation.

Since in some biodegradation experiments, FLX was expected to be the only carbon source it was necessary to perform previously a washing step to eliminate the carbon source (lactate). For this purpose, the enriched inoculum was centrifuged at $2500 \times \mathrm{g}$ for $10 \mathrm{~min}$ at room temperature, the supernatant was discarded, and the pellet re-suspended using the Postgate B without lactate or MSM. This procedure was repeated twice.

\subsection{Biodegradation of $F L X$}

Anaerobic cultures were prepared to evaluate the performance of the obtained bacterial community in terms of degradation of FLX.

The cultures were performed using $10 \%(\mathrm{v} / \mathrm{v})$ of the previously enriched inoculum on three different media spiked with FLX:

(i) a modified Postgate B medium (approximately $\mathrm{pH} 7$ ) used to growth SRB, composed by $0.5 \mathrm{~g} / \mathrm{L} \mathrm{KH}_{2} \mathrm{PO}_{4}, 1 \mathrm{~g} / \mathrm{L} \mathrm{NH}_{4} \mathrm{Cl}, 1 \mathrm{~g} / \mathrm{L}$ $\mathrm{Na}_{2} \mathrm{SO}_{4}, 1 \mathrm{~g} / \mathrm{L}$ yeast extract, $0.1 \mathrm{~g} / \mathrm{L}$ ascorbic acid, $0.1 \mathrm{~g} / \mathrm{L}$ thioglycolic acid, $2 \mathrm{~g} / \mathrm{L} \mathrm{MgSO}_{4} .7 \mathrm{H}_{2} \mathrm{O}$ and $7.75 \mathrm{~g} / \mathrm{L}$ of the carbon source $\mathrm{C}_{3} \mathrm{H}_{5} \mathrm{O}_{3} \mathrm{Na}$ (concentration of carbon source used in the standard Postgate B medium composition, thus the one that is considered the preferred for SBR growth) - sodium lactate and spiked with 20,50 and $100 \mathrm{mg} / \mathrm{L}$ FLX;

(ii) a modified Postgate $B$ medium without sodium lactate as carbon source but spiked with 20 and $50 \mathrm{mg} / \mathrm{L} \mathrm{FLX} \mathrm{as} \mathrm{sole}$ carbon source (approximately $\mathrm{pH} 7$ ). The concentration of $100 \mathrm{mg} / \mathrm{L}$ was not used in (ii) because in the previous assay (i) it was observed that this specific SRB community was not favoured by this drug concentration;

(iii) MSM (approximately $\mathrm{pH} 7$ ), a mineral salt medium a nonspecific medium without carbon compounds which was composed by $0.5 \mathrm{~g} / \mathrm{L} \mathrm{K}_{2} \mathrm{HPO}_{4}, 0.5 \mathrm{~g} / \mathrm{L} \mathrm{KH}_{2} \mathrm{PO}_{4}, 0.01 \mathrm{~g} / \mathrm{L} \mathrm{NaCl}$, $0.2 \mathrm{~g} / \mathrm{L} \mathrm{MgCl}_{2} \cdot 6 \mathrm{H}_{2} \mathrm{O}, 0.02 \mathrm{~g} / \mathrm{L} \mathrm{CaCl}_{2}, 0.0004 \mathrm{~g} / \mathrm{L} \mathrm{ZnSO} 4.7 \mathrm{H}_{2} \mathrm{O}$, $0.0004 \mathrm{~g} / \mathrm{L} \mathrm{CoCl}_{2} \cdot 6 \mathrm{H}_{2} \mathrm{O}, 0.0003 \mathrm{~g} / \mathrm{L} \mathrm{MnSO}_{4} \cdot \mathrm{H}_{2} \mathrm{O}, 0.01 \mathrm{~g} / \mathrm{L}$ EDTA and $0.0003 \mathrm{~g} / \mathrm{L}\left(\mathrm{NH}_{4}\right)_{6} \mathrm{Mo}_{7} \mathrm{O}_{24} \cdot 4 \mathrm{H}_{2} \mathrm{O}$ spiked with $50 \mathrm{mg} / \mathrm{L}$ FLX. The concentration of $50 \mathrm{mg} / \mathrm{L}$ FLX was chosen, since it was the highest one in which the SRB community grew, to check the bacteria that were able to degrade the drug and, also to evaluate the community behaviour without being under the sulphate reducing conditions as studied in the points (i) and (ii).

High concentrations of the drug were used to elucidate about the behaviour of the anaerobic consortium obtained under these conditions, and also to avoid that FLX could be growth limiting in the experiments where the drug was used as unique carbon source.

Another point is that if bacteria can degrade these higher concentrations, thus more effective may be the removal at much lower concentrations. This can be stated because despite the bacteria may prefer the available and easier to degrade carbon source in a medium such as wastewater rich in carbon sources, according to the BioWin predictive model, at these high concentrations it can be inferred that bacteria may be able to use this drug as carbon and/or energy source even in a complex medium [42].

All media were autoclaved $\left(120{ }^{\circ} \mathrm{C}\right.$ for $45 \mathrm{~min}$ ) and cooled to room temperature before the addition of FLX and inoculation, to prevent drug's degradation by heat. A stock solution of $1000 \mathrm{mg} / \mathrm{L}$ FLX was prepared in a volumetric flask of $250 \mathrm{~mL}$. To dissolve the 


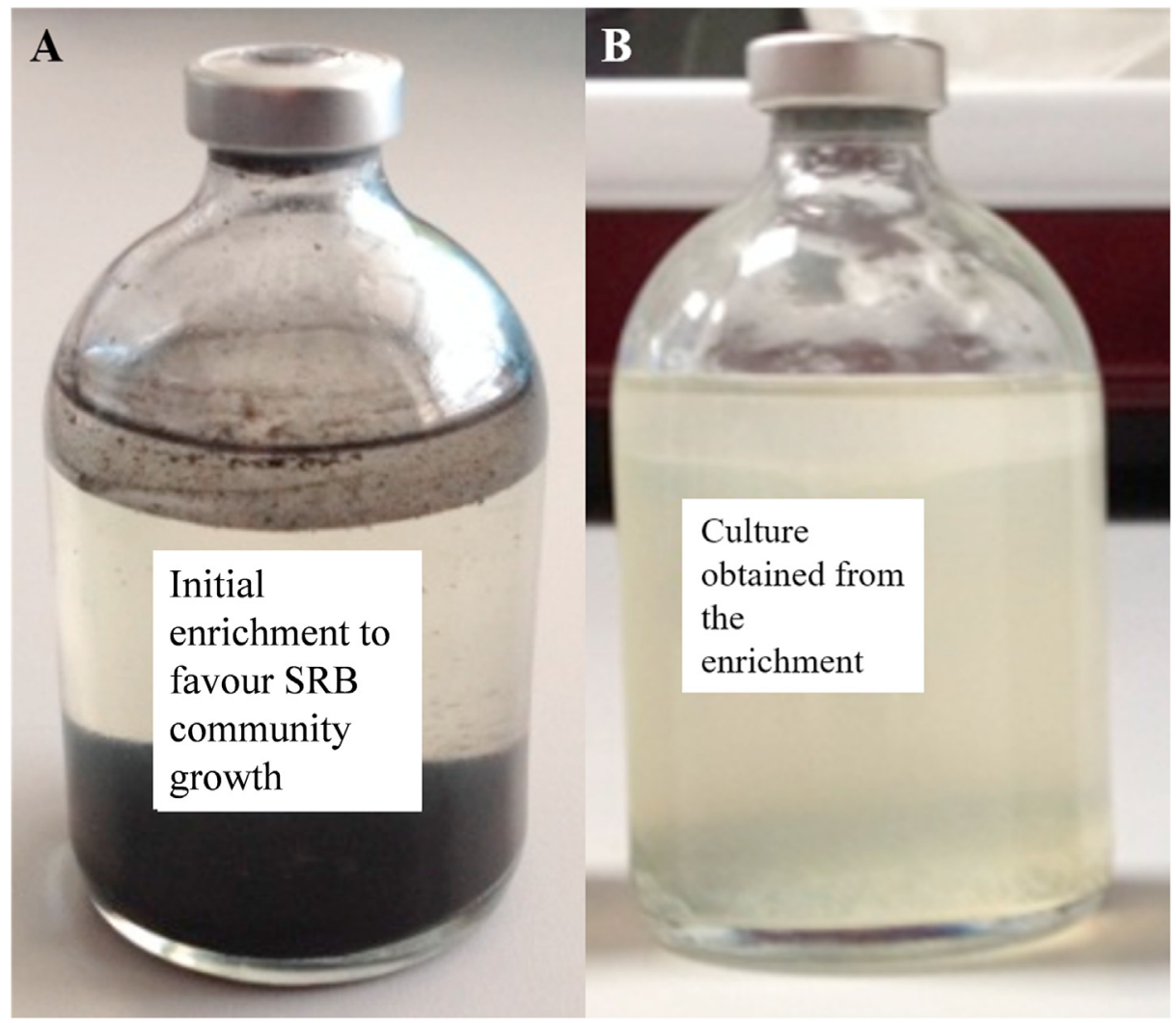

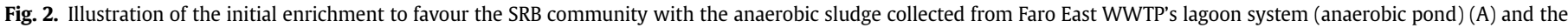
aspect of the inoculum used in the biodegradation assay, after 3 subcultures (B). The cultures in use were kept at room temperature.

powder about $150 \mu \mathrm{L}$ of methanol was used and then the volume was completed with milliQ water. To achieve each required concentration, the stock solution was added to the media using a polyethersulfone (PES) syringe filter of $0.2 \mu \mathrm{m}$ pore size from VWR (Leuven, Belgium) to avoid contamination in sterile conditions.

Negative controls were performed in the same manner as the biotic experiments, for all tested media to evaluate the eventual interactions of the drug with the medium or sludge (sorption). Moreover, to evaluate the possible adsorption of FLX onto the sludge used as inoculum, the sludge was autoclaved $\left(120^{\circ} \mathrm{C}\right.$ for $45 \mathrm{~min}$ ) to inactivate it, in Postgate B spiked with 20 and $50 \mathrm{mg} / \mathrm{L}$ FLX and in MSM media with $50 \mathrm{mg} / \mathrm{L}$ of this drug.

All the assays were carried out in triplicates, in dark conditions (to avoid photodegradation) at room temperature $\left(25 \pm 2{ }^{\circ} \mathrm{C}\right)$ and at atmospheric pressure without stirring. To create anaerobic conditions, a layer of liquid paraffin was added to cultures, acting as a barrier to prevent oxygen exchanges and the batch flasks were sealed with butyl rubber stoppers and aluminium crimp seals to avoid air intake into the flask.

The experiments in modified Postgate B were maintained for 31 days, more than the time to assure high SRB activity and total reduction of the sulphate in the growth media, according to the experience of the research group with these bacteria, namely for acid mine drainage bioremediation purposes [38-41]. The assays in MSM, a non-specific medium for SRB growth, were performed and maintained for 28 days, to verify which bacteria from the consortium other than the SRB could be able to use FLX as a carbon source. The formation of the putative metabolic products was also analysed during the degradation process (data not shown).

The summary of experimental set-ups used to evaluate FLX biodegradation is presented in Table 2.
Aiming to evaluate the SRB activity, $7 \mathrm{~mL}$ of each culture sample was collected using a syringe with a hypodermic needle for further analysis. The $\mathrm{pH}$, redox potential $\left(\mathrm{E}_{\mathrm{h}}\right)$, sulphate, $\mathrm{OD}_{600 \mathrm{~nm}}$ and chemical oxygen demand (COD) were immediately measured after collection. Fractions of $4 \mathrm{~mL}$ of each triplicate were stored at $-20^{\circ} \mathrm{C}$ for further DNA analysis. The cultures in Postgate $\mathrm{B}$ were monitored for $\mathrm{pH}$ and $\mathrm{E}_{\mathrm{h}}$ using a GLP $21 \mathrm{pH}$ meter, Crison (Barcelona, Spain). Sulphate concentration was determined by applying the sulfaVer4 method from Hach-Lange (Düsseldorf, Germany) through molecular UV/Visible spectroscopy at $450 \mathrm{~nm}$ using a Hach-Lange ${ }^{\mathrm{TM}} \mathrm{DR}$ 2800 spectrophotometer (Sköndal, Sweden). The bacterial growth was measured by OD performed at $600 \mathrm{~nm}$ in a Hach-Lange ${ }^{\mathrm{TM}} \mathrm{DR}$ 2800 spectrophotometer (Sköndal, Sweden).

\subsection{Quantification of FLX by high performance liquid chromatography (HPLC) analysis}

For the analysis, samples were prepared and separated as described in Ref. [43]. To analyse the biodegradation of FLX an HPLC analysis was performed using an isocratic method. The mobile phase consisted of acetonitrile (ACN): water $(75: 25, \mathrm{v} / \mathrm{v})$ adjusted to $\mathrm{pH} 2.87$ with orthophosphoric acid (85\%) with a flow rate of $1.0 \mathrm{~mL} /$ min, a total run time of $7 \mathrm{~min}$ and the column was maintained at room temperature. The eluents used were all HPLC grade provided by VWR Prolabo Chemicals (Fontenay-sous-Bois, France). The injection volume was $20 \mu \mathrm{L}$ and a wavelength of $204 \mathrm{~nm}$ was used for detection.

Specific standard calibration curves were constructed for each experiment to determine the concentrations of FLX (fluoxetine hydrochloride, solid, purity $\geq 98 \%$, Sigma-Aldrich (Deisenhofer, Germany)) in the corresponding samples. The concentration ranges 
Table 2

Summary of the assays used to evaluate FLX biodegradation.

\begin{tabular}{|c|c|c|c|c|c|}
\hline \multirow[b]{2}{*}{ Growth media } & \multirow{2}{*}{$\frac{\text { Conditions }}{\text { For Respiration }}$} & \multicolumn{2}{|l|}{ Inoculum source } & \multicolumn{2}{|l|}{ Carbon sources } \\
\hline & & Autoclaved inoculum & Anaerobic sludge (Faro's East WWTP) & Lactate $(\mathrm{mg} / \mathrm{L})$ & $\mathrm{FLX}(\mathrm{mg} / \mathrm{L})$ \\
\hline Modified Postgate B & Anaerobic & - & $\checkmark$ & 7750 & - \\
\hline \multirow[t]{3}{*}{ Modified Postgate B } & Anaerobic & $\checkmark$ & $\checkmark$ & 7750 & 20 \\
\hline & & $\checkmark$ & $\checkmark$ & & 50 \\
\hline & & $\checkmark$ & $\checkmark$ & & 100 \\
\hline \multirow[t]{2}{*}{ Modified Postgate B } & Anaerobic & $\checkmark$ & $\checkmark$ & - & 20 \\
\hline & & $\checkmark$ & $\checkmark$ & & 50 \\
\hline MSM & Anaerobic & $\checkmark$ & $\checkmark$ & - & 50 \\
\hline
\end{tabular}

$\checkmark=$ tested; $-=$ not added.

of FLX standards prepared with the respective medium were from 0.1 to $200 \mathrm{mg} / \mathrm{L}$ of the drug.

The limits of detection (LOD) were determined based on the series of measurement results for the standard solutions with the three lowest concentrations. A LOD of $0.26 \mathrm{mg} / \mathrm{L} \mathrm{FLX}$ was estimated. Based on the relationship LOQ (limit of quantification) $=3 \times$ LOD, the obtained LOQ was $0.78 \mathrm{mg} / \mathrm{L}$ FLX. The obtained working range was of $0.78 \div 100 \mathrm{mg} / \mathrm{L}$.

\subsection{Statistical analysis of data}

One-Way ANOVA (Single Factor) tests using Excel Data Analysis Tools were performed to evaluate the differences between the triplicates of cultures with inoculum in the absence or presence of the drug and the correspondent negative control (inactivated inoculum), with a significance level ( $\alpha$ ) of 0.05 . The ANOVA reports are presented in Figs. 3S and 4S of Supplementary Material.

\subsection{Fluoxetine biodegradation kinetics}

The removal efficiency (\%) was determined using (Equation 1):

FLX removal efficiency $(\%)=\frac{C_{0}-C_{t}}{C_{0}} \times 100$

where $C_{0}$ is the initial concentration of FLX at $\mathrm{t}=0$ and $C_{t}$ is the drug concentration over the assay, determined at $204 \mathrm{~nm}$.

Assuming, that the biodegradation of FLX follows a pseudo-first order kinetics, the experimental data were fitted in the equation

$C_{t}=C_{0} \times e^{-K_{a p p} t}$

where $\mathrm{k}_{\mathrm{app}}$ is the kinetic constant for degradation, $\mathrm{C}_{0}$ and $\mathrm{C}$ are the concentrations of the drug at time zero and at a given time, respectively and $t$ is the experimental time (days). In the cases, where the drug was not detectable, the final concentration was given by the lowest value detected (LOD), to estimate the kinetic parameters. The estimation of half-life of fluoxetine is defined by the time necessary for drug decay from the initial value to $50 \%$ and is given by

$t_{1 / 2}=\frac{0.693}{K_{a p p}}$

$\mathrm{K}_{\mathrm{app}}$ is the estimated apparent pseudo-first order degradation rate constant [41].

\subsection{Evaluation of fluoxetine effect on chemical oxygen demand} (COD)

$\operatorname{COD}\left(\mathrm{mg} \mathrm{O}_{2} / \mathrm{L}\right)$ is a measure of water and wastewater quality. This parameter was analysed during the assays in the presence and absence of FLX aiming to evaluate its contribution for COD and the impact of this drug on the removal of the organic material present in anaerobic experiments. Initial and final values were collected using a syringe with a hypodermic needle just after inoculation and after 7, 14, 28 and 31 days of incubation, respectively. COD measurements were carried out following the procedure described in Palma et al. [43].

\subsection{Sorption studies of FLX onto inactivated sludge}

The adsorption experiments were performed as described in section 2.2. of Material and Methods. To study the sorption mechanism of FLX onto inactivated sludge, Langmuir and Freundlich equilibrium adsorption isotherm models were applied. The Langmuir model is employed in cases where the adsorption of an ideal monolayer takes place on a homogeneous surface [44], which is expressed by:

\section{Langmuir equation (4):}

$\frac{1}{q_{e}}=\frac{1}{q_{\max \times K_{L} \times C_{e}}}+\frac{1}{q_{\max }}$

where $q_{e}$ is the amount of FLX adsorbed at equilibrium $(\mathrm{mg} / \mathrm{g})$ and $C_{e}$ corresponds to the drug concentration at equilibrium in the medium (mg/L).

In the Langmuir equation, $q_{\max }(\mathrm{mg} / \mathrm{g})$ is the measure of adsorption capacity/efficiency under the experimental conditions and $B_{L}$ is a constant related to the free energy of adsorption [44].

The Freundlich isotherm generally fits on a nonideal adsorption on heterogeneous surfaces and multilayer sorption, where theoretically exist a great and many diverse kinds of accessible sites acting simultaneously, each with a different free energy of sorption [45], which is expressed by:

Freundlich equation (5):

$\log q_{e}=\log K_{F}+\frac{1}{n} \log C_{e}$

The Freundlich treatment uses the parameters: $(1 / n)$ which is an empirical constant where the value of $n$, reveals the adsorption intensity (bonding energy) also allowing to understand the sorption process, and $K_{F}(\mathrm{mg} / \mathrm{g})$ which is related to adsorption capacity [45].

The experimental data fit into a pseudo-second order kinetic rate law thus, the study of biosorption of FLX onto inactivated sludge was carried out in the way proposed by Ho and McKay [46] expressed by:

Equation for pseudo-second order rate (6): 


$$
\frac{1}{q_{t}}=\frac{t}{q_{e q}}+\frac{1}{K_{2 \times} q_{e q}^{2}}
$$

where $q_{e q}$ and $q_{t}(\mathrm{mg} / \mathrm{g})$ are the amounts of adsorbed FLX on the biosorbent (sludge) at equilibrium and at time t, respectively and the second order biosorption rate constant is given by $K_{2}(\mathrm{~g} /$ mg.day). Pseudo-second-order rate model assumes that chemical sorption involves valency forces via sharing or exchange of electrons between the sorbent and sorbate and this is the rate-limiting step $[46,47]$.

\subsection{Molecular characterization of FLX degrading bacterial communities}

The microbial dynamics was studied through a massive sequencing of 16S rRNA genes on anaerobic cultures, to identify taxa putatively involved in the degradation of FLX and/or its metabolites. Microbial communities were studied along the anaerobic experiments, in cultures of Postgate B medium with 20 and $50 \mathrm{mg} / \mathrm{L}$ FLX and MSM of $50 \mathrm{mg} / \mathrm{L}$ of FLX in which the drug was used as sole carbon source. The three replicates correspondent to each experiment, condition and date of culture were pooled together. Thus, to identify microorganisms putatively capable of degrading FLX, the DNA was extracted, analysed, and sequenced as described in Ref. [43].

The raw massive sequencing data from 16S rRNA gene amplicons generated in this work was archived in the NCBI Sequence Read Archive (SRA) database under SRA study SRP159619 and BioProject PRJNA486835 repository, https://www.ncbi.nlm.nih. gov/sra/SRP159619; https://submit.ncbi.nlm.nih.gov/subs/ bioproject/SUB4426770/overview.

\section{Results and discussion}

\subsection{Anaerobic biodegradation of FLX}

The anaerobic cultures used in the biodegradation experiments started by an inoculum of a bacterial community from a Faro's East WWTP lagoon system sludge which was previously enriched in modified Postgate B medium under anaerobic conditions for 7 days to favour the growth of SRB. The SRB are a unique physiological group of prokaryotes because they have the ability of using sulphate as the final electron acceptor in respiration [48], that can be found in many reduced environments, such as anaerobic sludge [49]. SRB were found to grow on environmental contaminants such as petroleum hydrocarbon (PHC) constituents (e.g., benzene, toluene, ethylbenzene, xylenes, naphthalene, phenanthrene, and alkanes) and halogenated compounds [49-52]. Thus, in the present work, the obtained anaerobic community was tested for its FLX biodegradation ability.

\subsubsection{Cultures in the presence of sodium lactate and FLX as} supplementary carbon source under anaerobic conditions

Initially, FLX removal was studied in anaerobic cultures, where 20,50 and $100 \mathrm{mg} / \mathrm{L}$ of the drug was added simultaneously with $7.75 \mathrm{~g} / \mathrm{L}$ of sodium lactate (carbon source used in the standard Postgate B medium composition) [53] under sulphate reducing conditions as described in Table 2.

The effect produced by FLX on the growth and activity of SRB consortium was evaluated. Thus, simultaneously with the measurement of the bacterial growth given by the $\mathrm{OD}_{600 \mathrm{~nm}}$, sulphate concentration (Fig. 3 ) and activity parameters such as $\mathrm{pH}, \mathrm{E}_{\mathrm{h}}$ (Fig. $1 \mathrm{~S}$ of Supplementary material) and FLX concentrations were analysed during the experiments, in order, to investigate the drug removal by the SRB anaerobic consortium (Fig. 3).

The obtained experimental data for FLX degradation in the presence of lactate by the anaerobic community fit a kinetic of pseudo-first order due to the linear behaviour with a correlation coefficient $\left(\mathrm{R}^{2}\right)$ between 0.80 and 0.92 (Table 3 ) and this occurs when the rate of the process is proportional to the concentration of only one reactant despite the involvement of other reactant species in the reaction.

The $\mathrm{pH}$ of SRB cultures media spiked with 20,50 and $100 \mathrm{mg} / \mathrm{L}$ FLX was adjusted to approximately 7 (Fig. 1Sa of Supplementary material). The $\mathrm{pH}$ values remained constant throughout the experiment for all the drug concentrations tested and were within the optimum pH range for SRB growth which are between 5 and 8 $[48,53,54]$.

In the cultures of SRB without and in the presence of 20 and $50 \mathrm{mg} / \mathrm{L}$ of the FLX, the $\mathrm{E}_{\mathrm{h}}$ of the media started around $-100 \mathrm{mV}$ and decreased over the course of the days reaching $-400 \mathrm{mV}$, indicating SRB activity and consequent reduction of sulphate into sulphide. In the cultures spiked with $100 \mathrm{mg} / \mathrm{L}$ of FLX, the decrease of $E_{h}$ was up to $-200 \mathrm{mV}$ remaining practically constant afterward (Fig. 1Sb of Supplementary material). This is corroborated by a slight decrease in sulphate concentration and is associated to a lower bacterial growth and activity.

In the anaerobic cultures (mainly constituted by SRB) spiked with $20 \mathrm{mg} / \mathrm{L}$ FLX, the sulphate reduction into sulphide was about $83 \pm 1 \%$, therefore significantly faster $(p<0.05)$ than in positive cultures without the drug $(75 \pm 3 \%)$, after 14 days of incubation.

However, the reduction of sulphate into sulphide in a concentration of approximately $500 \mathrm{mg} / \mathrm{L} \mathrm{S}^{2-}$ was similar for both $20 \mathrm{mg} / \mathrm{L}$ FLX and positive control cultures, with values of about $98.0 \% \pm 0.2 \%$ corresponding to a removal rate of $0.166 \pm 0.004 \mathrm{~d}^{-1}$, $\mathrm{R}^{2}=0.92 \pm 0.02$ and $97 \pm 1 \%$ with a removal rate of $0.14 \pm 0.02 \mathrm{~d}^{-1}$, $\mathrm{R}^{2}=0.95 \pm 0.07$, respectively after 28 days of assay (Fig. 3a). The enhanced sulphate reduction in the presence of $20 \mathrm{mg} / \mathrm{L}$ of FLX can be explained by the fact that at this concentration the drug can also serve as complementary carbon source for bacterial growth in addition to lactate, although further studies are needed to complement this statement. Kleikemper et al. [49] already described that some SRB were able to use a variety of organic carbon sources, and the enhanced sulphate reduction was concomitant with carbon source degradation. Agreeing with the previous results, it was at $20 \mathrm{mg} / \mathrm{L}$ FLX that occurred the highest and fastest bacterial growth given by an $\mathrm{OD}_{600 \mathrm{~nm}}$ of $0.75 \pm 0.03$, after 14 days, while in the positive control without drug the bacterial growth was of $0.69 \pm 0.02$, after 14 days (Fig. $3 \mathrm{~b}$ ). At $20 \mathrm{mg} / \mathrm{L}$ FLX concentration, the most of the drug's degradation was observed during the growth phase, reaching removal values below the LOD at the end of the stationary phase after 21 days of assay (Fig. 3b). The removal efficiency was assumed to be almost total since the drug's limit of detection was reached at a rate of $0.249 \pm 0.004 \mathrm{~d}^{-1}$ with a $\mathrm{R}^{2}$ of $0.80 \pm 0.06$ (Table 3 ), following a pseudo-first order kinetics, after 21 days of incubation. The estimated FLX's half-life $\left(t_{1 / 2}\right)$ was of $2.79 \pm 0.04$ days. The results obtained at this FLX concentration showed a significant $(\mathrm{p}<0.05)$ drug removal when compared with the correspondent negative controls (inactivated inoculum), thus representing non-significant contribution of the adsorption mechanism (Table 3).

For cultures with $50 \mathrm{mg} / \mathrm{L}$ FLX, the sulphate concentration decreased significantly $(\mathrm{p}<0.05)$ during the assay, with percentages of $41 \pm 5 \%, 52 \pm 2 \%$ and $76 \pm 4 \%$, after 14,21 and 28 days of experiment (Fig. 3a). The sulphate removal rate was of $0.054 \pm 0.006 \mathrm{~d}^{-1}$ and $\mathrm{R}^{2}$ of $0.96 \pm 0.02$. The maximum value of bacterial growth obtained for cultures spiked with $50 \mathrm{mg} / \mathrm{L} \mathrm{FLX} \mathrm{was}$ given by an $\mathrm{OD}_{600 \mathrm{~nm}}$ of $0.39 \pm 0.05$, after 21 days of assay (Fig. $3 \mathrm{~b}$ ). At this concentration of FLX the removal of the drug occurred 


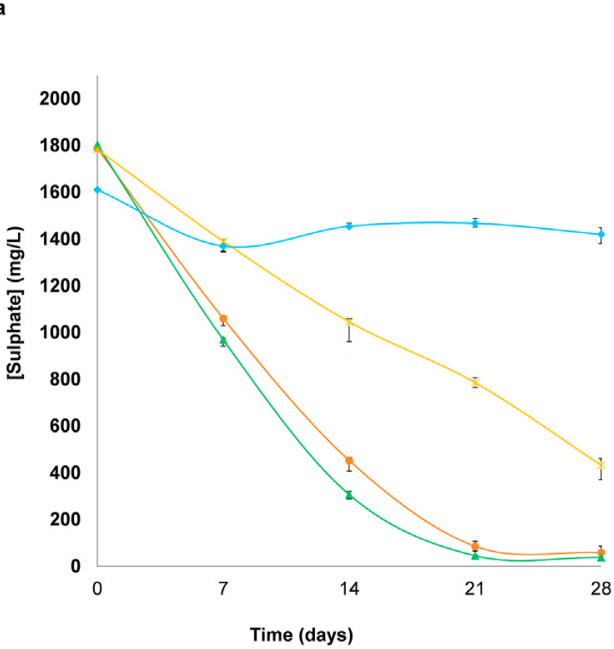

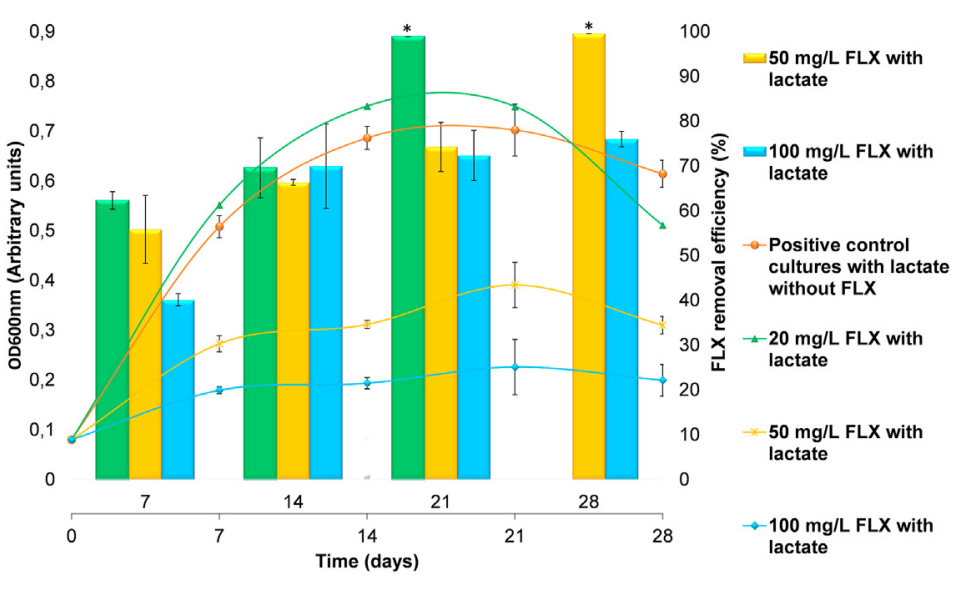

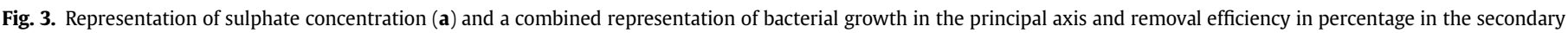

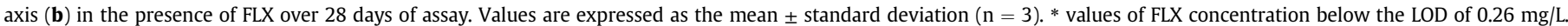

Table 3

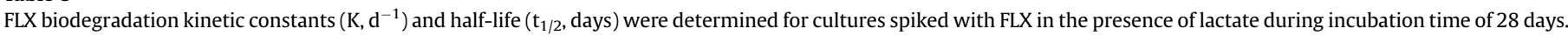

\begin{tabular}{|c|c|c|c|c|}
\hline Fluoxetine (mg/L) & Linear equation & $\mathrm{K}\left(\mathrm{d}^{-1}\right)$ & $\mathrm{R}^{2}$ & $\mathrm{t}_{1 / 2}$ (half-life, days) \\
\hline 20 & $\mathrm{y}=0.249 \pm 0.004 \mathrm{x}-1.3 \pm 0.1$ & $0.249 \pm 0.004$ & $0.80 \pm 0.06$ & $2.79 \pm 0.04$ \\
\hline 50 & $\mathrm{y}=0.21 \pm 0.02 \mathrm{x}-1.3 \pm 0.2$ & $0.21 \pm 0.02$ & $0.87 \pm 0.08$ & $3.3 \pm 0.4$ \\
\hline 100 & $y=0.09 \pm 0.07 x+0.6 \pm 0.4$ & $0.09 \pm 0.07$ & $0.92 \pm 0.08$ & $13 \pm 8$ \\
\hline
\end{tabular}

mainly in the exponential phase. However, from the 7th to the 14th, the consortium appeared to achieve a stationary phase that occurred likely due to an adaptation process which is later explained by the bacterial community shift. Nevertheless, FLX continued to be removed even after the bacterial growth had cessed and was assumed to be already completed in the decline phase after 28 days (Fig. 3b). The removal efficiency was assumed to be almost complete since the drug's LOD was reached, at a rate of $0.2 \pm 0.02 \mathrm{~d}^{-1}$ with a $\mathrm{R}^{2}$ of $0.87 \pm 0.08$ (Table 3 ), after 28 days of incubation.

In the negative control with $50 \mathrm{mg} / \mathrm{L}$ FLX the drug removal decreased from $42 \pm 12 \%$ after 21 days to $14 \pm 2 \%$ after 28 days of incubation, which may be due to desorption of the drug, or to chemical interactions between FLX and the culture medium compounds. Despite this, the adsorption of the drug to the sludge was also non-significant at $50 \mathrm{mg} / \mathrm{L}$ of FLX compared with the cultures with inoculum at the same drug concentration.

Moreira et al. [27] described a system where FLX was removed through adsorption and a mechanism of adsorption and desorption during a reactor operation.

For cultures with $100 \mathrm{mg} / \mathrm{L}$ FLX, sulphate reduction was not significant $(\mathrm{p}>0.05)$ as indicated by the values obtained: $12 \pm 2 \%$ after 28 days of incubation, which corresponds to a very low removal rate of $0.0014 \pm 0.0009 \mathrm{~d}^{-1}$. This is in agreement with the low $\mathrm{OD}_{600 \mathrm{~nm}}$ values $0.23 \pm 0.06$ after 21 days of experiment (Fig. 3b). In the negative control (inactivated inoculum) in which no bacterial activity was expected, there was neither a significant sulphate reduction nor bacterial growth (Fig. 3a and b). From the results it can be inferred that the SRB bacteria were not growing at $100 \mathrm{mg} / \mathrm{L} \mathrm{FLX}$ and that this concentration seems to be toxic to this specific group of bacteria. However, other bacteria resistant to FLX may have arisen in the community. The removal efficiency was assumed to be $76 \%$ at a rate of $0.09 \pm 0.07 \mathrm{~d}^{-1}$ with a $\mathrm{R}^{2}$ of $0.92 \pm 0.08 \%$. Thus the hypothesis that another bacteria than SRB were growing can be supported by the fact that $76 \pm 2 \%$ of $100 \mathrm{mg} / \mathrm{L}$ of FLX was removed and was significantly higher $(\mathrm{p}<0.05)$ than the corresponding negative control with inactivated sludge $(60 \pm 2 \%)$, after 28 days of assay (Fig. 3b). However, in this case it seems to have been a contribution from both adsorption mechanism and bacterial activity (biodegradation processes).

Although the biodegradation appeared to not have been due to SRB activity, other bacteria belonging to this community may be involved in the removal of FLX, thus, being responsible for the drug's biodegradation.

\subsubsection{Cultures in the presence FLX as sole carbon source under anaerobic conditions}

Several studies demonstrated that organic compounds can be used either as carbon source and/or as terminal electron acceptors for bacterial growth [43,52,55-57]. The enriched community containing SRB inoculum was cultured in Postgate B (sulphate reducing conditions) spiked with 20 and $50 \mathrm{mg} / \mathrm{L}$ FLX as unique carbon source, in anaerobic conditions, to study the ability of this consortium to growth and use FLX. Negative (medium with inactivated sludge) and positive (medium with lactate) controls were also performed (Table 2).

Simultaneously the drug removal (use as only carbon source) by the anaerobic consortium was investigated (Fig. 4).

The experimental data for FLX degradation when the drug was used as sole carbon source fitted a kinetic of pseudo-first order due to the linear behaviour with correlation coefficients $\left(R^{2}\right)$ varying between 0.79 and 0.90 (Table 4).

The $\mathrm{pH}$ remained neutral (about 7) for all the tested FLX concentrations and positive control (Fig. 2Sa of Supplementary material). The redox potential of the culture media spiked with 20 and $50 \mathrm{mg} / \mathrm{L}$ FLX as unique carbon source and of the positive control, evolved from $-100 \mathrm{mV}$ to values between -350 and $-400 \mathrm{mV}$, which showed the SRB activity (Fig. 1Sb of Supplementary 

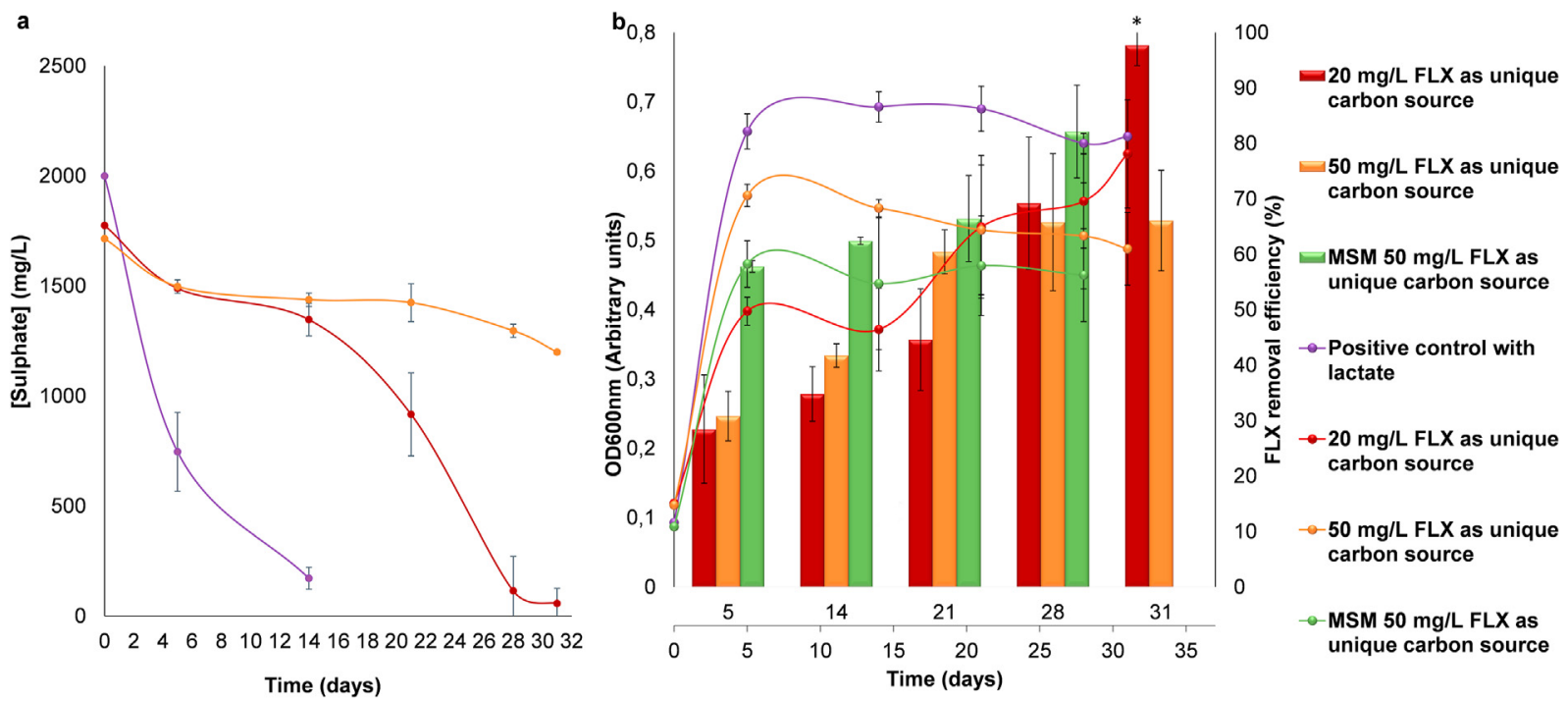

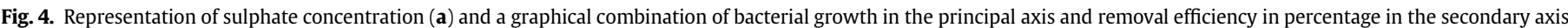

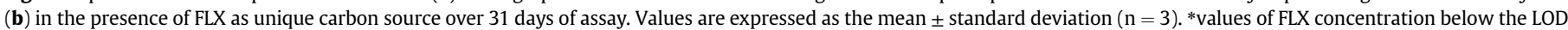
of $0.26 \mathrm{mg} / \mathrm{L}$.

Table 4

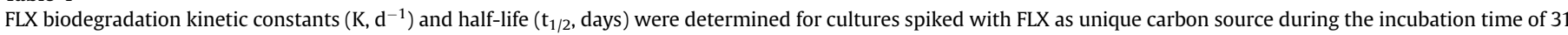
days.

\begin{tabular}{|c|c|c|c|c|}
\hline Fluoxetine (mg/L) & Linear equation & $\mathrm{K}\left(\mathrm{d}^{-1}\right)$ & $\mathrm{R}^{2}$ & $\mathrm{t}_{1 / 2}$ (days) \\
\hline 20 & $\mathrm{y}=0.2 \pm 0.1 \mathrm{x}-2 \pm 1$ & $0.2 \pm 0.1$ & $0.73 \pm 0.12$ & $6 \pm 5$ \\
\hline 50 & $\mathrm{y}=0.03 \pm 0.01 \mathrm{x}+0.2 \pm 0.1$ & $0.03 \pm 0.01$ & $0.87 \pm 0.09$ & $26 \pm 13$ \\
\hline 50MSM & $\mathrm{y}=0.05 \pm 0.02 \mathrm{x}+0.5 \pm 0.1$ & $0.05 \pm 0.02$ & $0.90 \pm 0.02$ & $16 \pm 5$ \\
\hline
\end{tabular}

material).

For the SRB cultures in the presence $20 \mathrm{mg} / \mathrm{L}$ FLX it was verified that the progression of sulphate reduction was slower at a removal rate of $0.17 \pm 0.06 \mathrm{~d}^{-1}, \mathrm{R}^{2}$ of 0.94 (completed only after 28 days), while in the positive control, the sulphate was reduced at residual concentrations with a removal rate of $0.211 \pm 0.009 \mathrm{~d}^{-1}, \mathrm{R}^{2}$ of 1 , after 14 days of incubation (Fig. 4a). At this concentration of FLX the bacterial growth was given by an $\mathrm{OD}_{600 \mathrm{~nm}}$ of $0.40 \pm 0.02$ after 5 days, remaining constant until the 14 th day. After that time, there was an increase in the bacterial growth up to $O D_{600 \mathrm{~nm}}$ values of $0.62 \pm 0.08$ after 31 days of incubation (Fig. 4 b). It should be noted that the $\mathrm{OD}_{600 \mathrm{~nm}}$ values of the positive control displayed their maximum of $0.69 \pm 0.02$ after 14 days (Fig. 4b). The behaviour showed by the growth curve of the cultures in the presence of $20 \mathrm{mg} / \mathrm{L} \mathrm{FLX}$ may be due to an adaptation of the consortium to the drug as carbon source. In the cultures spiked with $20 \mathrm{mg} / \mathrm{L} \mathrm{FLX}$ the drug removal percentages were of $28 \pm 10 \%, 44 \pm 9 \%, 69 \pm 12 \%$ and undetected values below the LOD, after $5,21,28$ and 31 days of incubation, respectively with a removal rate of $0.2 \pm 0.1 \mathrm{~d}^{-1}$ with $\mathrm{R}^{2}$ of $0.79 \pm 0.1$ (Fig. $4 \mathrm{~b}$ ). These results reveal that FLX maximum degradation occurred during the exponential phase, even though what appeared to be a kind of stationary phase between the 5th and 14th day, was likely an adaptation period, as demonstrated by the $\mathrm{OD}_{600 \mathrm{~nm}}$ values at $20 \mathrm{mg} / \mathrm{L}$ of FLX (Fig. 4b). At $20 \mathrm{mg} / \mathrm{L} \mathrm{FLX} \mathrm{the}$ drug removals increased significantly $(\mathrm{p}<0.05)$ compared with the negative controls $(6 \pm 3 \%, 15 \pm 2 \%, 12 \pm 4 \%$ and $11 \pm 5 \%)$ during the course of the experiment, suggesting bacterial degradation of FLX.

On the other hand, for cultures spiked with $50 \mathrm{mg} / \mathrm{L}$ of FLX, the percentage of sulphate reduction was $31 \pm 4 \%$ at a removal rate of $0.009 \pm 0.001 \mathrm{~d}^{-1}, \mathrm{R}^{2}$ of $0.94 \pm 0.01$, after 31 days of experiment (Fig. 4a). Although sulphate reduction was not significant during the experiment, the $\mathrm{OD}_{600 \mathrm{~nm}}$ values were of $0.56 \pm 0.02$ and $0.49 \pm 0.05$ after 5 and 31 days, respectively, remaining always constant during the assay and meaning that bacterial consortium growth occurred (Fig. 4b). At $50 \mathrm{mg} / \mathrm{L}$ FLX the percentages of drug removal obtained for the inoculated tests $(31 \pm 4 \%$ and $42 \pm 2 \%)$ were not significantly different $(p>0.05)$ from the negative controls ( $17 \pm 8 \%$ and $32 \pm 7 \%$ ), after 5 and 14 days of incubation, respectively. However, during the remaining incubation period, the percentages of FLX removal were of $60 \pm 4 \%, 65 \pm 12 \%$ and $66 \pm 9 \%$ and significantly higher $(\mathrm{p}<0.05)$ than in the negative controls $(27 \pm 1 \%, 6 \pm 3 \%$ and $6 \pm 5 \%$ ) (Fig. 4b). Following a pseudo-first order, FLX was removed by the consortium with an efficiency of approximately $66 \%$ at a rate of $0.03 \pm 0.01 \mathrm{~d}^{-1}$ with a $\mathrm{R}^{2}$ of $0.87 \pm 0.09$, with a half-life $\left(t_{1 / 2}\right)$ of $26 \pm 13$ days. The removal of the drug continued after the end of the exponential phase (7th day) and continued during the stationary phase until the last day (31st) of assay (66 $\pm 9 \%$ ) (Fig. 4b). These results are in accordance with those obtained for bacterial growth and activity, despite the low sulphate reduction at $50 \mathrm{mg} / \mathrm{L}$ FLX (Fig. $4 \mathrm{a}$ and b). At this concentration NFLX, a secondary metabolite generated during the FLX biodegradation experiment (data not shown), was detected.

Once more, these results suggest the possible growth of other bacteria than SRB, that belong to the consortium and were able to grow and use that concentration of FLX as carbon source.

As expected in the negative controls the redox potential remained above $-100 \mathrm{mV}$ and the $\mathrm{OD}_{600 \mathrm{~nm}}$ did not suffer changes remaining very low $(\mathrm{OD} \approx 0.1)$. Also, the sulphate was not converted along the 31 days of assay (Fig. $4 a$ and b).

As described in the Material and Methods section, this community was also cultured in MSM, an inorganic medium, spiked with $50 \mathrm{mg} / \mathrm{L}$ of FLX used as the only carbon source available 
(Table 2). The assay with this non-specific medium and without being under sulphate reducing conditions was performed to evaluate which bacteria from this community other than SRB can growth in the presence of this drug. In this assay it was possible to verify bacterial growth with $\mathrm{OD}_{600 \mathrm{~nm}}$ values of $0.47 \pm 0.03$ and $0.45 \pm 0.07$ were observed after 5 and 28 days of incubation (Fig. 4b). Also, the $\mathrm{E}_{\mathrm{h}}$ decreased from $261 \mathrm{mV}$ to $-300 \mathrm{mV}$ (data not shown) revealing that some activity of SRB appeared to occur, although the medium was not specific for their growth.

In the case of the inoculated cultures in MSM spiked with $50 \mathrm{mg} / \mathrm{L}$ FLX, the removal of FLX was of $58 \pm 1 \%$, thus significantly higher $(\mathrm{p}<0.05)$ than in the negative control (inactivated inoculum), which was $33 \pm 4 \%$, after 5 days of experiment. The removal achieved in the inoculated cultures $(66 \pm 8 \%)$ was not significantly different $(p>0.05)$ from the results obtained in the negative control ( $54 \pm 14 \%$ ), after 21 days of experiment. However, in these cultures the removal was about $82 \pm 8 \%$ with a removal rate of $0.05 \pm 0.02$ with a $R^{2}$ of $0.90 \pm 0.02$, which is significantly higher $(p<0.05)$ compared with the result of the inactivated inoculum ( $53 \pm 5 \%$ ), after 28 days of assay (Fig. 4$)$. The half-life $\left(t_{1 /}\right.$ 2) of the drug in these conditions was of $16 \pm 5$ days. Thus, the results in MSM medium suggest that in addition to biodegradation other mechanisms such as adsorption to the sludge, or drug interactions with the medium components, may have a contribution for FLX removal.

Despite this, it seems that the SRB present in this consortium were not the only bacteria involved in FLX removal, once it was possible to observe bacterial growth and activity in Postgate B cultures even when sulphate was not reduced, as well as in the MSM cultures. As demonstrated by the identification and characterization of the bacterial populations using 16S rRNA gene sequencing, other microorganisms than SRB, initially less abundant in the inoculum, may have been directly, or indirectly, responsible for the observed FLX removal.

\subsubsection{Effect of FLX on COD degradation}

COD was evaluated for all the biodegradation experiments performed in cultures with both lactate and FLX and with the drug as unique carbon source, the obtained values did not include biomass formation (Table 5 ).

The effect of FLX on COD values was practically null, since the values were similar measured in the culture media before the addition of FLX, prior inoculation, and after inoculation in the presence of the drug, of $2326 \mathrm{mgO}_{2} / \mathrm{L}$ and $2329 \mathrm{mgO}_{2} / \mathrm{L}$, respectively. In the experiments where bacteria grew only in the presence of lactate as unique carbon source (positive controls) the initial values of COD were $2404 \mathrm{mgO}_{2} / \mathrm{L}$ and during the assay only approximately $3.5 \pm 0.3 \%$ was removed after 31 days (Table 5 ). In all the negative controls no COD removal was detected.

The initial values of COD in the cultures with both FLX and lactate were $2349 \mathrm{mgO}_{2} / \mathrm{L}, 2336 \mathrm{mgO}_{2} / \mathrm{L}, 2340 \mathrm{mgO}_{2} / \mathrm{L}$ and 2330 $\mathrm{mgO}_{2} / \mathrm{L}$ at 20, 50 and $100 \mathrm{mg} / \mathrm{L}$ FLX, respectively, although they remained practically constant (without significant removal) during all the experiment (Table 5).

When FLX was used as sole carbon source, the initial values were $1425 \mathrm{mgO}_{2} / \mathrm{L}, 1499 \mathrm{mgO}_{2} / \mathrm{L}$ and $475 \mathrm{mgO}_{2} / \mathrm{L}$ for $20,50 \mathrm{mg} / \mathrm{L}$ FLX in Postgate B without lactate and $50 \mathrm{mg} / \mathrm{L}$ FLX in MSM, respectively. During the experiment it was observed that COD removal efficiency progressively increased to $37 \pm 10 \%$, $25.27 \pm 0.02 \%$ and $28 \pm 20 \%$ at 20 and $50 \mathrm{mg} / \mathrm{L} \mathrm{FLX}$ under sulphate reducing conditions and at $50 \mathrm{mg} / \mathrm{L}$ FLX in MSM, respectively, after 31 days of assay. The highest removal percentages of COD, $45 \pm 4 \%$ and $37 \pm 8 \%$, were obtained in the cultures of MSM with $50 \mathrm{mg} / \mathrm{L} \mathrm{FLX}$, after 14 and 28 days of incubation (Table 5).

The incubation occurred in batch without stirring, these 
Table 6

The constant values obtained from Langmuir and Freundlich isotherms models on FLX adsorption onto sludge at experimental conditions.

\begin{tabular}{|c|c|c|c|c|c|c|c|c|}
\hline \multirow[t]{2}{*}{ Carbon source } & \multirow[t]{2}{*}[\mathrm{FLX}]{$(\mathrm{mg} / \mathrm{L})$} & \multicolumn{3}{|c|}{ Langmuir isotherm model } & \multicolumn{4}{|c|}{ Freundlich isotherm model } \\
\hline & & $\mathrm{B}_{\mathrm{L}}(\mathrm{L} / \mathrm{mg})$ & $\mathrm{q}_{\text {máx }}(\mathrm{mg} / \mathrm{g})$ & $\mathrm{R}^{2}$ & $\operatorname{LogK}_{\mathrm{f}}(\mathrm{L} / \mathrm{mg})$ & $\mathrm{K}_{\mathrm{f}}(\mathrm{mg} / \mathrm{g})$ & $\mathrm{n}_{\mathrm{f}}$ & $\mathrm{R}^{2}$ \\
\hline FLX & 20 & -0.08 & 1.15 & 0.9935 & 4.81 & $6.5 \times 10^{4}$ & -0.30 & 0.998 \\
\hline+ & 50 & -0.03 & 2.99 & 0.9517 & 5.84 & $6.9 \times 10^{5}$ & -0.34 & 0.984 \\
\hline Lactate & 100 & -0.03 & 19.61 & 0.9738 & 3.73 & $5.4 \times 10^{3}$ & -0.83 & 0.994 \\
\hline \multirow[t]{3}{*}{ FLX (without lactate) } & 20 & -0.06 & 0.24 & 0.9582 & 11.74 & $5.50 \times 10^{11}$ & -0.11 & 0.9857 \\
\hline & 50 & -0.03 & 1.38 & 0.5247 & 11.93 & $8.5 \times 10^{11}$ & -0.14 & 0.8528 \\
\hline & MSM50 & -0.07 & 9.61 & 0.9565 & 3.12 & $1.32 \times 10^{3}$ & -0.81 & 0.989 \\
\hline
\end{tabular}

conditions may be unfavourable for a complete COD removal, since as is well known, processes without recirculation could be ineffective in soluble organic compounds removal $[58,59]$. The anaerobic cultures where both FLX and lactate were used presented negligible removal percentages of COD likely due to an excess of lactate which possibly was not all consumed by bacteria, which in addition to the presence of FLX could generate an overload of organic compounds, plus the products generated by the bacterial growth and metabolism. However, in cultures where FLX was used as unique carbon source a decrease of COD was verified.

This led to the following possible explanations: (i) the unfavourable conditions of the experiment (without stirring and recirculation) for COD removal; (ii) excess of carbon sources which are not all being consumed by bacteria; and (iii) the presence of slow degradable organic compounds (such as the metabolites generated by FLX degradation, e.g. NFLX) [43].

\subsubsection{Sorption studies of FLX onto inactivated sludge}

To investigate the interactions of the adsorbate (FLX) onto the adsorbent surface (sludge), the Langmuir and Freundlich equilibrium isotherms were estimated for FLX adsorption on the inactivated sludge for all the experimental conditions tested (Table 6).

As shown in Table 1, FLX has certain physico-chemical properties that tend to favour sorption interactions. In addition, another characteristic that suggests interactions between sludge and drug rely on the fact that FLX is positively charged while the sludge is typically negatively charged at $\mathrm{pH}$ 7. Despite all these favourable conditions the sorption mechanism does not occur always in the same way.

To elucidate about the adsorption capacity of the adsorbent (inactivated sludge) and the equilibrium interactions between the drug (adsorbate) and sludge (adsorbent), equilibrium analysis using Langmuir and Freundlich isotherms were performed. The Langmuir and Freundlich isotherms parameters, can be determined by a regression of the experimental data giving a ratio between the quantity adsorbed and the remaining in solution at equilibrium. A higher Langmuir constant $\left(B_{\mathrm{L}}\right)$ indicates that there is a strong interaction/affinity between the adsorbate and adsorbent, while a smaller value suggests weak interactions. In this case, the Langmuir model did not fit the obtained experimental data since a negative intercept was obtained, which is considered physically impossible
[60], despite the good linearity and the high correlation coefficients, $\mathrm{R}^{2}>0.95$, with exception of cultures Postgate B with $50 \mathrm{mg} / \mathrm{L}$ FLX, where the $\mathrm{R}^{2}$ was 0.5247 (Table 6). This can occur due to the energetic heterogeneity of adsorption sites in an adsorbate such as sludge that is mainly constituted by cells and organic compounds that could contribute to the obstruction of adsorption sites, decreasing the binding energy between the surfaces [61].

However, the values of $\mathrm{q}_{\mathrm{max}}(\mathrm{mg} / \mathrm{g}$ ) which are the measure of adsorption capacity under the experimental conditions display values that seem to agree with the removal percentages obtained in the inactivated sludge. For example, at $100 \mathrm{mg} / \mathrm{L}$ FLX, where the highest removal was verified ( $60 \pm 2 \%$ ), qmáx was also the highest 19.61 (mg/g) (Table 6), the same trend for MSM spiked with $50 \mathrm{mg} /$ L FLX where the removal was $53 \pm 5 \%$ and qmáx was 9.61 .

The parameters for Freundlich isotherm model were determined and the adsorption intensity or bonding energy given by ( $\mathrm{n}$ ) was always negative thus, less than 1 , suggesting that the adsorbent (sludge) presents a higher interaction for the solvent than for the sorbent (FLX), generating an unfavourable adsorption. However, the values of $\mathrm{K}_{\mathrm{F}}$ that indicate the adsorption intensity/capacity (high $\mathrm{K}_{\mathrm{F}}$ greater the adsorption intensity) are extremely high, revealing a strong capacity for FLX adsorption onto sludge. Once more it seems that the sorption process does not fit the assumption of Freundlich approach, and a possible explanation is that this model is not suitable at high concentrations. An important limitation of the Freundlich equation is that it does not describe a limit in adsorption capacity; theoretically, the amount adsorbed may be infinite as solute concentration increases [62].

It can be concluded that current adsorption data does not match neither with Langmuir nor Freundlich models.

\subsubsection{Adsorption kinetics of FLX onto inactivated sludge}

The experimental data fit into a pseudo-second order rate law, thus the kinetic study of FLX biosorption onto inactivated sludge was carried out in the way proposed by Ho and McKay [46], where $\mathrm{q}_{\mathrm{eq}}$ and $\mathrm{q}_{\mathrm{t}}(\mathrm{mg} / \mathrm{g})$ are the amounts of adsorbed FLX on the biosorbent (sludge) at equilibrium and at time $t$, respectively and the second order biosorption rate constant is given by $\mathrm{K}_{2}$ (g/mg.day). This model assumes that chemical sorption involves valency forces via sharing or exchange of electrons between the sorbent and sorbate and this is the rate-limiting step $[46,47]$. The obtained

Table 7

Sorption kinetics of FLX onto inactivated sludge was studied applying a pseudo-second order rate proposed by Ho and McKay [46].

\begin{tabular}{|c|c|c|c|c|c|c|}
\hline \multirow[t]{2}{*}{ Carbon source } & \multirow[t]{2}{*}[\mathrm{FLX}]{$(\mathrm{mg} / \mathrm{L})$} & \multicolumn{5}{|l|}{ Pseudo-second order kinetics } \\
\hline & & Equation & $\mathrm{K}_{2}$ (g/mg.day) & $\mathrm{q}_{\text {eq }}(\mathrm{mg} / \mathrm{g})$ & $\mathrm{q}_{\text {eq, experimental }}(\mathrm{mg} / \mathrm{g})$ & $\mathrm{R}^{2}$ \\
\hline FLX & 20 & $\mathrm{y}=0.0820 \pm 0.0007 \mathrm{x}+1.19 \pm 0.08$ & $0.0056 \pm 0.0003$ & $12.2 \pm 0.1$ & $6 \pm 2$ & $0.92 \pm 0.07$ \\
\hline \multirow{2}{*}{ + lactate } & 50 & $\mathrm{y}=0.11 \pm 0.05 \mathrm{x}-0.2 \pm 0.4$ & $-0.02 \pm 0.04$ & $11 \pm 6$ & $12 \pm 4$ & $0.92 \pm 0.06$ \\
\hline & 100 & $\mathrm{y}=0.020 \pm 0.007 \mathrm{x}+0.11 \pm 0.06$ & $0.005 \pm 0.004$ & $56 \pm 23$ & $41 \pm 11$ & $0.94 \pm 0.09$ \\
\hline \multirow[t]{3}{*}{ FLX (without lactate) } & 20 & $\mathrm{y}=0.4 \pm 0.1 \mathrm{x}+1.6 \pm 0.9$ & $0.1 \pm 0.1$ & $3 \pm 1$ & $2 \pm 1$ & $0.94 \pm 0.03$ \\
\hline & 50 & $y=0.7 \pm 0.4 x-5 \pm 4$ & $-0.09 \pm 0.04$ & $2 \pm 2$ & $7 \pm 5$ & $0.85 \pm 0.09$ \\
\hline & MSM50 & $\mathrm{y}=0.031 \pm 0.001 \mathrm{x}+0.17 \pm 0.04$ & $0.006 \pm 0.002$ & $31 \pm 1$ & $23 \pm 5$ & $0.87 \pm 0.11$ \\
\hline
\end{tabular}




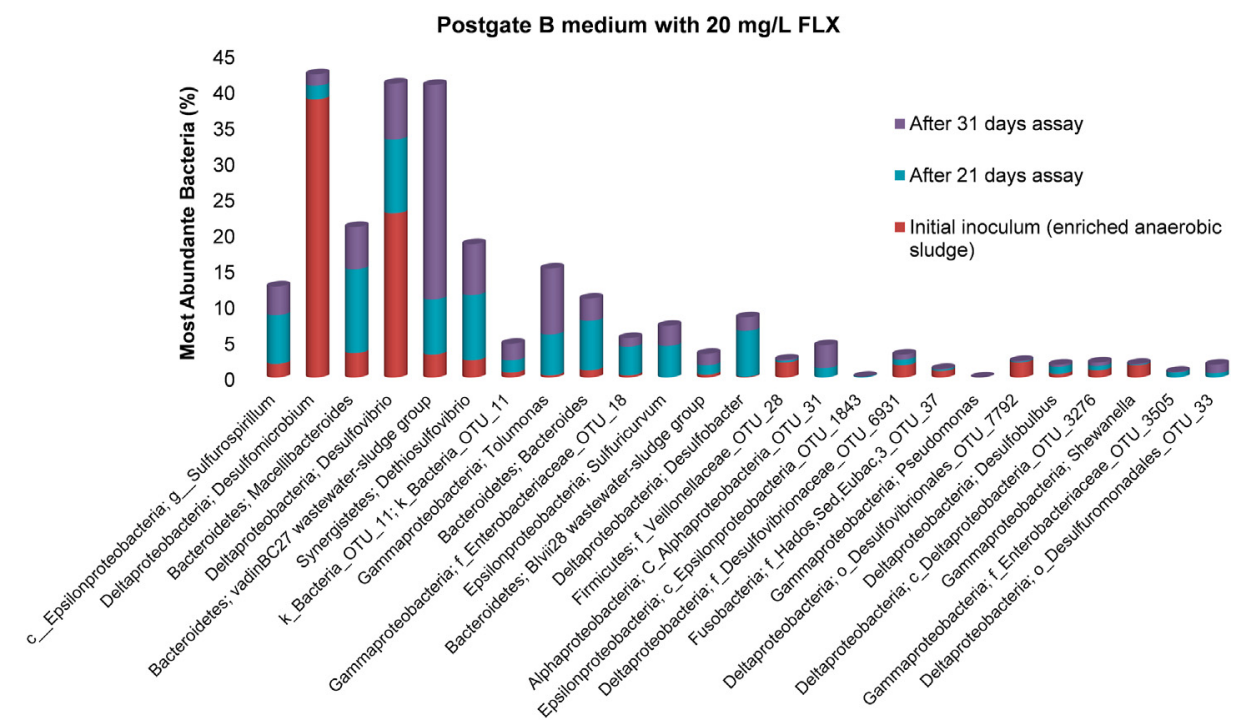

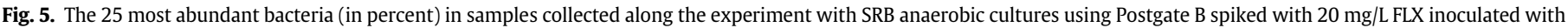
$10 \%(\mathrm{v} / \mathrm{v})$ of enriched sludge from the WWTP lagoon system. Each bacterium has both a broad group name (phylum) and more specific names (genus and/or family).

results are presented in Table 7.

The experimental data show compatibility with the pseudosecond order equation and the regression coefficients for the linear plots were higher than 0.90 for all the inactivated cultures with exception of both assays where $50 \mathrm{mg} / \mathrm{L}$ was used (Table 7). Also, the equilibrium sorption capacity obtained using the intercept of the equation give reasonable values suggesting that the sorption process follows a pseudo-second order reaction (Table 7).

The value of $\mathrm{q}_{\mathrm{eq}}(\mathrm{mg} / \mathrm{g})$ (sorption capacity at equilibrium) estimated for inactivated cultures with Postgate B in the presence of lactate and $20 \mathrm{mg} / \mathrm{L} \mathrm{FLX}$, was the double of the experimental ones (maybe due to chemical interferences), while for the other inactivated cultures the obtained $\mathrm{q}_{\mathrm{eq}}$ values were in accordance with the experimental $\mathrm{q}_{\mathrm{eq} \text {,exp }}$, since they are near the obtained experimentally. As expected, the highest sorption capacity of $56 \pm 23 \mathrm{mg} / \mathrm{g}$ was achieved at $100 \mathrm{mg} / \mathrm{L} \mathrm{FLX,} \mathrm{where} \mathrm{the} \mathrm{removal} \mathrm{percentage} \mathrm{of} \mathrm{the}$ drug $(60 \pm 2 \%)$ was also the highest, which suggests that FLX adsorption onto inactivated sludge can play a role on drug's elimination at this high concentration of the drug.

\subsection{Molecular characterization of the selected FLX biodegrading} communities and investigation of their dynamics by phylogenetic analysis of $16 S$ rRNA gene

Bacterial DNA was extracted from the promising biodegradation assays corresponding to Postgate B spiked with 20 and $50 \mathrm{mg} / \mathrm{L} \mathrm{FLX}$ as sole carbon source and MSM cultures with $50 \mathrm{mg} / \mathrm{L} \mathrm{FLX}$ as carbon source.

The identification of the bacterial communities was performed by $16 \mathrm{~S}$ rRNA gene sequencing for bacterial identification using a $16 \mathrm{~S}$ rRNA amplicon sequence data for the V1-3 regions of the 16S rRNA.

The 25 most abundant bacterial groups were given in percentages of $16 \mathrm{~S}$ rRNA gene amplicons (Fig. 5). Thus, the initial inoculum from an enriched sulphate-reducing bacteria culture was mainly constituted by two members of the genera Desulfomicrobium (38.8\%) and Desulfovibrio (22.9\%) from the class Deltaproteobacteria. During the degradation of $20 \mathrm{mg} / \mathrm{L}$ FLX in Postgate B medium a clear shift of the community occurred with a pronounced decrease of the initial population. Thus, after 21 and 31 days of assay the relative abundances of Desulfomicrobium were $1.9 \%$ and $1.6 \%$, while for Desulfovibrio were $10.3 \%$ and $7.8 \%$, respectively
(Fig. 5). This indicates that Desulfomicrobium and Desulfovibrio populations were affected by the presence of the FLX as only carbon source.

Over the incubation time of the experiment in the presence of $20 \mathrm{mg} / \mathrm{L}$ FLX, a gradual increase in the percentages of 16S rRNA gene amplicons occurred for genera vadinBC27 wastewater-sludge group, with $3.2 \%$ in the initial inoculum to $7.7 \%$ and $29.9 \%$ after 28 and 31 days of assay, respectively. In addition to vadinBC27 wastewater-sludge group, also the initial population of Macellibacteroidetes (3.4\%), Dethiosulfovibrio (2.4\%), Bacteroides (1\%), Desulfobacter (0.1\%), Tolumonas (0.3\%), Sulfurospirillum (1.9\%), Sulfuricurvum (0\%), f_Enterobacteriaceae_OTU_18 (0.3\%), Alphaproteobacteria_OTU_31 (0\%), o_Desulfuromonadales_OTU_33 (0\%) increased to $(11.7 \%, 9.1 \%, 6.9 \%, 6.4 \%, 4 \%, 6.8 \%, 4.4 \%, 5.7 \%, 1.3 \%, 0.6 \%)$ and $(5.9 \%, 7.1 \%, 3.1 \%, 1.9 \%, 1.2 \%, 4 \%, 2.8 \%, 9.2 \%, 3.2 \%, 1.2 \%)$ after 21 and 31 days of experiment, respectively (Fig. 5), suggesting that the representatives of these genera in this population may be involved in FLX and its metabolic products degradation. However, none of these genera are described in the literature as FLX degraders.

In the inoculated cultures spiked with $20 \mathrm{mg} / \mathrm{L} \mathrm{FLX}$ all the sulphate was reduced. That can be explained by the presence of the resistant and bioactive SRB population mainly composed by Desulfovibrio, Desulfomicrobium, Desulfobacter and Desulfobulbus, which were initially of $22.9 \%, 38.8 \% 0.1 \%$ and $0.5 \%$, whereas after 21 days of experiment their relative abundances were of $19.3 \%, 1.9 \%$, $6.4 \%$ and $1 \%$ respectively (Fig. 5). It is important to mention that Sulfurospirillum and Desulfuromonas are elemental sulphur reducing bacteria, Dethiosulfovibrio is a thiosulphate or sulphur reducing bacteria and Sulfuricurvum, species can derive energy from the oxidation of elemental sulphur or sulphur reduced compounds (sulphide, sulphite) [63].

To our knowledge, these bacteria herein identified as the most abundant were not reported in literature as degrading FLX, nevertheless they were described in the literature as having capacity to biodegrade other organic pollutants.

The genus vadinBC27 wastewater-sludge group was found for the first time in a vinasse anaerobic digester [64]. The genera vadinBC27 wastewater-sludge group together with Desulfovibrio, Enterobacter and Desulfobulbus could contribute to the decomposition of hardly-degradable organic pollutants in landfill leachate [65], such as nitroaromatic pollutants reducing nitroaromatics to 
the corresponding aromatic amines [66]. However, in addition to this information nothing more is found in the literature about the genus vadin $B C 27$ wastewater-sludge group, but since its capacity to degrade aromatic compounds was already reported, this genus could be one of the major responsible for FLX decomposition at $20 \mathrm{mg} / \mathrm{L}$ FLX.

Zhang et al. [67] hypothesized that Macellibacteroides and Desulfomicrobium were the key functional genera in anaerobic environments. Macellibacteroides and Desulfomicrobium were found to work together in WWTPs processes with a high proportion of textile dye wastewater from an industry. Zhang et al. [67] inferred that within sewage treatment plants that treat dye industry wastewater containing aromatic hydrocarbons, the dominant genera of their anaerobic system would likely consist of aromatic hydrocarbon degrading bacteria, predominantly fermentative ones, such as Macellibacteroides, and sulphate and sulphur reducing bacteria, such as Desulfomicrobium, Desulfovibrio, Desulfobacter, Desulfuromonas, Sulfurospirillum.

Also, Tolumonas which were herein found among the 25 most abundant bacteria, are known for their ability to produce toluene from phenylalanine, phenylpyruvate, phenyl lactate, and phenylacetate, and phenol [68].

Wang et al. [69] found that after the addition of the pharmaceuticals and personal care products (PPCPs) (ibuprofen, naproxen, prednisolone, norfloxacin and sulphamethoxazole), the relative abundance of Tolumonas increased from $0.51 \%$ to $3.76 \%$. Therefore, they speculated that Tolumonas could have a role on biodegradation of antibacterial and anti-inflammatory organic matter.

Giacomucci et al. [70] found that Desulfovibrio desulfuricans ATCC 1354, genus herein identified among the most abundant bacteria, was able to degrade nitrocellulose, a binder in paint that is recalcitrant to degradation.

There is no description in the literature about degradation of fluorinated compounds by SRB communities, however they revealed to be able to biodegrade other recalcitrant pollutants.
Miralles et al. [71] investigated sediments contaminated with a high quantity of oil and found that a wide variety of aliphatic hydrocarbons were significantly biodegraded by bacterial communities after 503 days under environmental conditions at $20 \mathrm{~m}$ water depth. They found that shifts in SRB community are a dynamic phenomenon since bacterial diversity seems to be influenced by the complexity of the mixtures of hydrocarbons. Miralles et al. [71] reported that Desulfovibrio-Desulfomicrobium-like bacteria as several other sulphate-reducing bacteria were capable of oil, alkane or benzene, toluene, ethylbenzene and xylene (BTEX) degradation and to mineralize BTEX and polycyclic aromatic hydrocarbons (PAHs) compounds under anaerobic conditions [71,72].

Luijten et al. [73] investigated members of the genus Sulfurospirillum, that was herein identified as one of the 25 most abundant genus, and demonstrated that this genus has a broad and diverse substrate range. Ross et al. [74] reported that Sulfurospirillum spp. played an important role in sulphur and nitrogen cycling and possesses a metabolic flexibility that enables the reduction of a wide variety of electron acceptors, including thiosulfate, tetrathionate, polysulfide, nitrate, and nitrite. Sulfurospirillum is recognized to specifically reduce sulphur and oxidized metals such as arsenate and selenite [73]. The isolation of strain PCE-M2T, a novel halorespiring ("respiring halogenated compounds") species, demonstrated the importance of the genus Sulfurospirillum in the biotransformation of contaminated soils with chlorinated compounds and metal ions. Sulfurospirillum halorespirans can use tetrachloroethylene, selenate, arsenate, nitrate, nitrite, sulphur and fumarate as final electron acceptors [73]. Thus, anaerobic microorganisms may be able to degrade a wide range of halogenated compounds [73].

Starting from the same enriched anaerobic inoculum used for the experiments in the presence of $20 \mathrm{mg} / \mathrm{L} \mathrm{FLX}$, inoculated cultures in Postgate B medium spiked with $50 \mathrm{mg} / \mathrm{L}$ FLX as unique carbon source were performed (Fig. 6).

It was also evidenced that a clear shift occurred from the initial

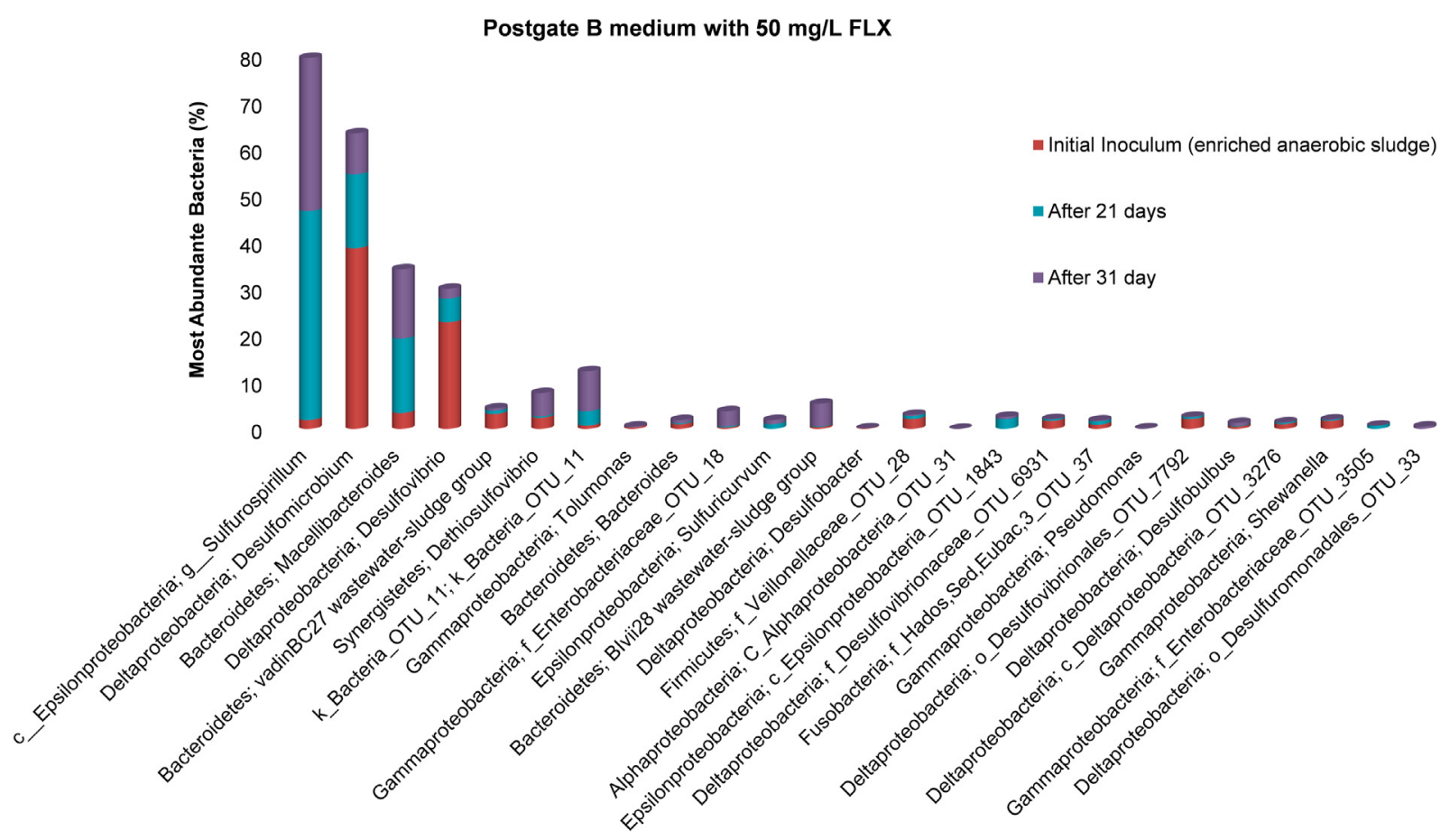

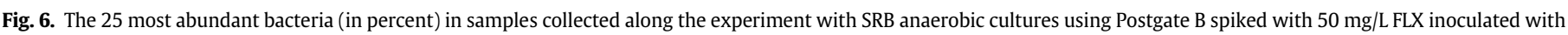
$10 \%(\mathrm{v} / \mathrm{v})$ of enriched sludge from the WWTP lagoon system. Each bacterium has both a broad group name (phylum) and more specific names (genus and/or family). 


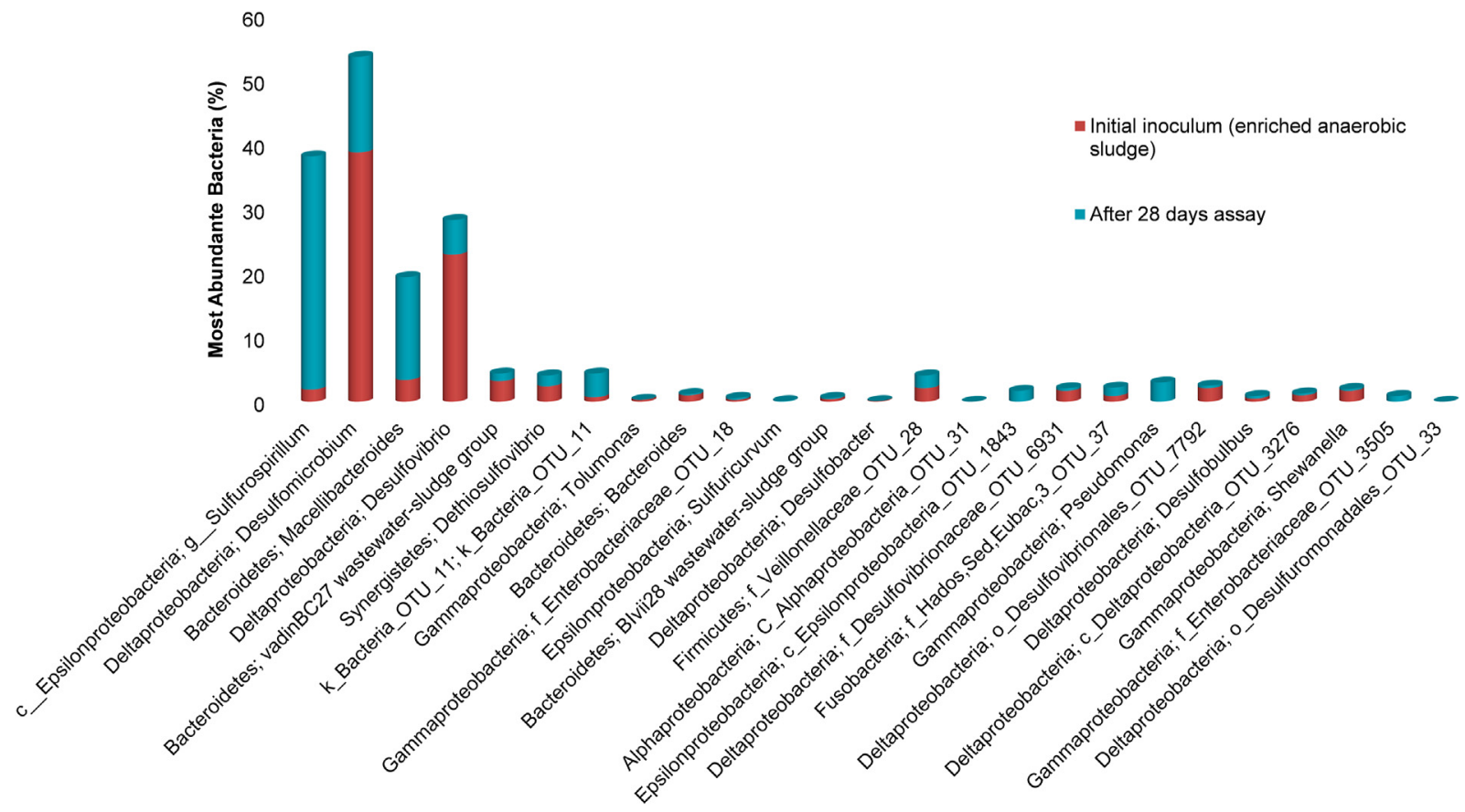

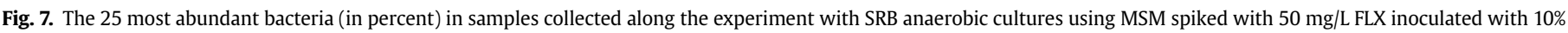
$(\mathrm{v} / \mathrm{v})$ of enriched sludge from the WWTP lagoon system. Each bacterium has both a broad group name (phylum) and more specific names (genus and/or family).

community. In addition, during the experiment these community revealed to be different in terms of genera percentages than the existing during the assays with $20 \mathrm{mg} / \mathrm{L}$ FLX.

Initially, Desulfomicrobium (38.8\%) was dominant, followed by Desulfovibrio (22.9\%), whereas the percentages of 16S rRNA gene amplicons for genera Sulfurospirillum (1.9\%), Macellibacteroidetes (3.4\%), Dethiosulfovibrio (2.4\%), BIvii28 wastewater sludge group an anaerobic fermenter (0.4\%), k_Bacteria_OTU_11 (0.7\%), f_Enterobacteriaceae_OTU_18 (0.3\%) became more abundant (i.e. $32.9 \%$, $14.9 \%, 5 \%, 4.9 \% 8.6 \%, 3.3 \%$, respectively) after 31 days of the experiment in the presence of $50 \mathrm{mg} / \mathrm{L}$ FLX (Fig. 6). This shift from the initial community indicates that the SRB community structure was affected by the presence of FLX. Nevertheless, the results suggest that the representatives of these genera in this population may also be involved in FLX and its metabolic products degradation.

Although all the sulphate was converted when $20 \mathrm{mg} / \mathrm{L}$ of FLX was used as carbon source, only $24 \%$ of sulphate was converted for $50 \mathrm{mg} / \mathrm{L}$ of the drug. That can be explained due the existence of a higher percentage of sulphate-reducing bacteria (e.g. Desulfobacter) in the community grown in the presence of $20 \mathrm{mg} / \mathrm{L}$ FLX than in that grown in the presence of $50 \mathrm{mg} / \mathrm{L}$. In the latter case, a huge reduction of SRB occurred, giving rise to another group of bacteria, the sulphur-reducing bacteria (e.g. Sulfurospirillum), which uses elemental sulphur as energetic source. Thus, this community shifted during the assay to one that was mostly constituted by genera that uses other electron acceptors instead of sulphate.

Martins, Sanches and Pereira [75] reported that the lower abundance of Desulfovibrio spp. in the absence of a carbon source (ethanol) likely explains why sulphate was not reduced, showing that these organisms were not able to use ciprofloxacin (a fluoroquinolone antibiotic) as carbon source for reduction of sulphate. They suggested that SRB can contribute to attenuate ciprofloxacin in anaerobic environments where sulphate is a common electron acceptor, such as WWTP, estuarine sediments and sea water [75].
Other explanation may be that the existing SRB bacteria in the presence of such high concentration of FLX became inactive.

In the assay where the community was inoculated in MSM medium, under non-specific reductive conditions, in the presence of $50 \mathrm{mg} / \mathrm{L}$ FLX as the only carbon source, once more a clear shift of the initial inoculum occurred (Fig. 7).

However, the population presents some similarities to the one inoculated with Postgate B spiked with $50 \mathrm{mg} / \mathrm{L} \mathrm{FLX.} \mathrm{Thus,} \mathrm{over} \mathrm{the}$ course of the assay there was an increase in the genera Sulfurospirillum from 1.9 to $36.3 \%$, Macellibacteroides from 3.4 to $16 \%$, k_Bacteria_OTU_11 from 0.7 to $3.7 \%$, Pseudomonas from 0 to $3 \%$, c_Epsilonproteobacteria_OTU_1843 from 0 to $1.7 \%$ and finally f_Enterobacteriaceae_OTU_3505 from 0 to $0.9 \%$, after 28 days of incubation (Fig. 7). This also suggests that the representatives of these genera in this population can possibly degrade FLX and subsequently its metabolic products.

It was possible to verify that at both $20 \mathrm{mg} / \mathrm{L}$ and $50 \mathrm{mg} / \mathrm{L} \mathrm{FLX} \mathrm{a}$ shift occurred in the bacterial community giving rise to identical populations being the most abundant bacteria belonging to the genera e.g. Sulfurospirillum, Macellibacteroides, Dethiosulfovibrio, $k$ _Bacteria_OTU_11, $f$ _Enterobacteriaceae_OTU_18, although in varying abundances, which reinforce that these common genera may be responsible for FLX removal (Figs. 5-7). In the lower concentration of $20 \mathrm{mg} / \mathrm{L}$ FLX, vadinBC27 wastewater-sludge group, Tolumonas, Bacteroides and Desulfobacter appear to have an important role in FLX removal because they were the most abundant. However, they did not seem to adapt well to $50 \mathrm{mg} / \mathrm{L} \mathrm{FLX,}$ which is suggested by the decrease in their relative abundances (Figs. 5-7).

It was not possible to successfully isolate the "most abundant" bacteria which belong to the consortium, which suggests that they may not be able to grow isolated from the other bacteria in the presence of the FLX.

To our knowledge, the microorganisms herein identified have 
never been described in the literature as FLX degrading organisms, although they have been mentioned as having the ability to degrade other recalcitrant organic pollutants.

The obtained results can be important to foster the study of the slightly explored anaerobic processes and for further development of anaerobic biological technologies to treat hazardous and recalcitrant pharmaceutical wastewaters.

\section{Conclusions}

Although information on anaerobic degradation of organic compounds under sulphate reducing conditions are scarce and remain to explore, the results herein obtained indicate that the studied anaerobic SRB community played a major role in the biodegradation of FLX. These results may allow the development of new anaerobic processes aiming the degradation of compounds containing very strong C-F bonds, such as FLX, which are recalcitrant to aerobic degradation. The anaerobic SRB consortium cultured in Postgate B with lactate and FLX as an additional carbon source, degraded $20 \mathrm{mg} / \mathrm{L}$ and $50 \mathrm{mg} / \mathrm{L}$ until undetectable concentrations, after 28 and 31 days, respectively and was able to degrade $76 \pm 2 \%$ of $100 \mathrm{mg} / \mathrm{L}$ FLX in the end of assay. In the experiments under sulphate reducing conditions where FLX was used as sole carbon source the consortium was able to degrade $20 \mathrm{mg} / \mathrm{L}$ FLX below the limits of detection and removed $66 \pm 9 \%$ of $50 \mathrm{mg} / \mathrm{L}$ of that drug. Although the Langmuir and Freundlich adsorption isotherms do not fit the experimental data, it seems that the adsorption mechanism plays a role in the removal of FLX mainly at the highest concentration of $100 \mathrm{mg} / \mathrm{L}$ FLX. Regarding the evolution of SRB community that displayed the ability to degrade FLX as sole carbon source, the initial population that was mainly constituted by Desulfomicrobium and Desulfovibrio suffered a shift during the removal of $20 \mathrm{mg} / \mathrm{L}$ FLX with an increase of members of the genera vadinBC27 wastewater-sludge group, Macellibacteroidetes, Dethiosulfovibrio, Bacteroides, Tolumonas, Sulfuricurvum, f_Enterobacteriaceae_OTU_18 that are assumed for the first time as having a possible role in FLX degradation. It is important to note that these bacteria were also identified among the most abundant genera together with Blvii28 wastewater-sludge group and k_Bacteria_OTU_11 during the degradation of $50 \mathrm{mg} / \mathrm{L}$ FLX as sole carbon source.

Although the main mechanism of FLX removal described in the literature is adsorption to sediments or sludge, in the results herein described, biodegradation, under anaerobic conditions, appears to have a major role in the degradation of this drug.

\section{Funding/acknowledgments}

The authors would like to thank Fundação para a Ciência e a Tecnologia for funding this research through the PhD grant SFRH/ BD/95075/2013 of Tânia Palma and through the Centro de Ciências do Mar's Plurianual (project UIDB/04326/2020). Financial support was obtained through project 0483_PROBIOMA_5_E, co-financed by the European Regional Development Fund within the framework of the Interreg V-A Spain-Portugal program (POCTEP) 2014-2020.

\section{Declaration of competing interest}

"The authors declare that they have no competing interests".

\section{Appendix A. Supplementary data}

Supplementary data to this article can be found online at https://doi.org/10.1016/j.anaerobe.2021.102356.

\section{Authors' contributions}

Tânia Palma carried out the experimental work and wrote the article as part of her PhD. Dr. Maria Clara Costa supervised the experimental work, corrected, and revised the manuscript.

\section{References}

[1] E. Vulliet, C. Cren-Olive, Screening of pharmaceuticals and hormones at the regional scale, in surface and ground waters intended to human consumption, Environ. Pollut. 159 (10) (2011) 2929-2934, https://doi.org/10.1016/ j.envpol.2011.04.033.

[2] V. Geissen, H. Mol, E. Klumpp, G. Umlauf, M. Nadal, M. van der Ploeg, S.E.A.T.M. van de Zee, C.J. Ritsema, Emerging pollutants in the environment: a challenge for water resource management, Int. Soil Water Conserv. Res. 3 (1) (2015) 57-65, https://doi.org/10.1016/j.iswcr.2015.03.002.

[3] J.C. Stevens, S. A, Wrighton Interaction of the enantiomers of fluoxetine and norfluoxetine with human liver cytochromes p450, J. Pharmacol. Exp. Therapeut. 266 (2) (1993) 964-971.

[4] P. Benfield, R.C. Heel, S.P. Lewis, Fluoxetine. A review of its pharmacodynamic and pharmacokinetic properties, and therapeutic efficacy in depressive illness, Drugs 32 (6) (1986) 481-508, https://doi.org/10.2165/00003495-19863206000002.

[5] M.J. Andrés-Costa, K. Proctor, M.T. Sabatini, A.P. Gee, S.E. Lewis, Y. Pico, B. Kasprzyk-Hordern, Enantioselective transformation of fluoxetine in water and its ecotoxicological relevance, Nat. Sci. Rep. 7 (2017) 15777, https:// doi.org/10.1038/s41598-017-15585-1.

[6] ChemSpider Database, Fluoxetine, 2019. http://www.chemspider.com/ Chemical-Structure.3269.html?rid=e52e351c-7a85-4d29-9754f390417f5249. (Accessed 3 August 2019).

[7] ChemSpider Database, Seproxine (Norfluoxetine), 2019. http://www. chemspider.com/Chemical-Structure.4382.html?rid=1ba12ed6-64d0-41b69fc9-afad1da74de5. (Accessed 3 August 2019).

[8] D.S. Wishart, Y.D. Feunang, A.C. Guo, E.J. Lo, A. Marcu, J.R. Grant, T. Sajed, D. Johnson, C. Li, Z. Sayeeda, N. Assempour, I. Iynkkaran, Y. Liu, A. Maciejewski, N. Gale, A. Wilson, L. Chin, R. Cummings, D. Le, A. Pon, C. Knox, M. Wilson, DrugBank 5.0: a major update to the DrugBank database for 2018, Nucleic Acids Res. (2017), https://doi.org/10.1093/nar/gkx1037.

[9] Y.F. Velázquez, P.M. Nacheva, Biodegradability of fluoxetine, mefenamic acid, and metoprolol using different microbial consortiums, Environ. Sci. Pollut. Res. Int. 24 (7) (2017) 6779-6793, https://doi.org/10.1007/s11356-017-8413y.

[10] S. Das, N.M. Ray, J. Wan, A. Khan, T. Chakraborty, M.B. Ray, Micropollutants in wastewater: fate and removal processes in: physico-chemical wastewater treatment and resource recovery, IntechOpen 5 (2017) 76-107, https:// doi.org/10.5772/65644s.

[11] M. Gros, M. Petrović, A. Ginebreda, D. Barceló, Removal of pharmaceuticals during wastewater treatment and environmental risk assessment using hazard indexes, Environ. Int. 36 (2010) 15-26.

[12] C.D. Metcalfe, S. Chu, C. Judt, H. Li, K.D. Oakes, M.R. Servos, D.M. Andrews, Antidepressants and their metabolites in municipal wastewater, and downstream exposure in an urban watershed, Environ. Toxicol. Chem. 29 (1) (2010) 79-89, https://doi.org/10.1002/etc.27.

[13] B. Petrie, R. Barden, B. Kasprzyk-Hordern, A review on emerging contaminants in wastewaters and the environment: current knowledge, understudied areas and recommendations for future monitoring, Water Res. 72 (2014) 3-27, https://doi.org/10.1016/j.watres.2014.08.053, 0.

[14] M. Carballa, F. Omil, J.M. Lema, Comparison of predicted and measured concentrations of selected pharmaceuticals, fragrances and hormones in Spanish sewage, Chemosphere 72 (8) (2008) 1118, https://doi.org/10.1016/ j.chemosphere.2008.04.034.

[15] D.R. Baker, B. Kasprzyk-Hordern, Spatial and temporal occurrence of pharmaceuticals and illicit drugs in the aqueous environment and during wastewater treatment: new developments, Sci. Total Environ. 454-455 (2013) 442-456, https://doi.org/10.1016/j.scitotenv.2013.03.043.

[16] L.J.G. Silva, A.M.P.T. Pereira, L.M. Meisel, C.M. Lino, A. Pena, A one-year followup analysis of antidepressants in Portuguese wastewaters: occurrence and fate, seasonal influence and risk assessment, Sci. Total Environ. 490 (2014) 279-287, https://doi.org/10.1016/j.scitotenv.2014.04.131.

[17] M.J. Benotti, R.A. Trenholm, B.J. Vanderford, J.C. Holady, B.D. Stanford, S.A. Snyder, Pharmaceuticals and endocrine disrupting compounds in U.S. drinking water, Environ. Sci. Technol. 43 (2009) 597-603, https://doi.org/ 10.1021/es801845a.

[18] B.W. Brooks, P.K. Turner, J.K. Stanley, J.J. Weston, E.A. Glidewell, C.M. Foran, M. Slattery, T.W. La Point, D.B. Huggett, Waterborne and sediment toxicity of fluoxetine to select organisms, Chemosphere 52 (1) (2003) 135-142, https:// doi.org/10.1016/S0045-6535(03)00103-6.

[19] P.P. Fong, P.T. Huminski, L.M. D'Urso, Induction and potentiation of parturition in Fingernail clams (Sphaerium Striatinum) by selective serotonin re-uptake Inhibitors (SSRIs), J. Exp. Zool. 280 (3) (1998) 260-264, https://doi.org/ 10.1002/(SICI)1097-010X(19980215)280:3<260::AID-JEZ7>3.0.CO;2-L.

[20] L.J.G. Silva, C.M. Lino, L.M. Meisel, A. Pena, Selective serotonin re-uptake 
inhibitors (SSRIs) in the aquatic environment: an ecopharmaco vigilance approach, Sci. Total Environ. 437 (2012) 185-195. http://www.ncbi.nlm.nih. gov/pubmed/22940043.

[21] L.H. Santos, A.N. Araújo, A. Fachinia, A. Pena, C. Delerue-Matos, M.C. Montenegro, Ecotoxicological aspects related to the presence of pharmaceuticals in the aquatic environment, J. Hazard Mater. 175 (1-3) (2010) 45-95, https://doi.org/10.1016/j.jhazmat.2009.10.100.

[22] J. Weinberger, R. Klaper, Environmental concentrations of the selective serotonin reuptake inhibitor fluoxetine impact specific behaviors involved in reproduction, feeding and predator avoidance in the fish Pimephales promelas (fathead minnow), Aquat. Toxicol. 151 (2014) 77-83, https://doi.org/10.1016/ j.aquatox.2013.10.012.

[23] W. Shi, Y. Han, X. Guan, J. Rong, W. Su, S. Zha, Y. Tang, X. Du, G. Liu, Fluoxetine suppresses the immune responses of blood clams by reducing haemocyte viability, disturbing signal transduction and imposing physiological stress, Sci. Total Environ. 683 (2019) 681-689, https://doi.org/10.1016/ j.scitotenv.2019.05.308.

[24] J.W. Kwon, K.L. Armbrust, Laboratory persistence and fate of fluoxetine in aquatic environments, Environ. Toxicol. Chem. 25 (10) (2006) 2561-2568, https://doi.org/10.1897/05-613R.1.

[25] C.A. Kinney, E.T. Furlong, S.L. Werner, J.D. Cahill, Presence and distribution of wastewater-derived pharmaceuticals in soil irrigated with reclaimed water, Environ. Toxicol. Chem. 25 (2) (2006) 317-326, https://doi.org/10.1897/05187R.1.

[26] A.C. Cartwright, B.R. Mattheus, International pharmaceutical product registration, Drugs and the pharmaceutical sciences, Informa Healthcare 200 (2010) second ed.

[27] I.S. Moreira, C.L. Amorim, A.R. Ribeiro, R.B.R. Mesquita, A.O.S.S. Rangel, M.C.M. van Loosdrecht, M.E. Tiritan, P.M.L. Castro, Removal of fluoxetine and its effects in the performance of an aerobic granular sludge sequential batch reactor, J. Hazard Mater. 287 (2015) 93-101, https://doi.org/10.1016/ j.jhazmat.2015.01.020.

[28] I.S. Moreira, A.R. Ribeiro, C.M. Afonso, M.E. Tiritan, P.M.L. Castro, Enantioselective biodegradation of fluoxetine by the bacterial strain Labrys portucalensis F11, Chemosphere 111 (2014) 103-111, https://doi.org/10.1016/ j.chemosphere.2014.03.022.

[29] B.M. Peake, R. Braund, A.Y.C. Tong, L.A. Tremblay, The Life-Cycle of Pharmaceuticals in the Environment, first ed., Woodhead Publishing, 2015.

[30] M.W. Lam, C.J. Young, S.A. Mabury, Aqueous photochemical reaction kinetics and transformation of fluoxetine, Environ. Sci. Technol. 39 (2) (2005) 513-522, https://doi.org/10.1021/es0494757.

[31] K.D. Oakes, A. Coors, B.I. Escher, K. Fenner, J. Garric, M. Gust, T. Knacker, A. Küster, C. Kussatz, C.D. Metcalfe, S. Monteiro, T.W. Moon, et al., Environmental risk assessment for the serotonin re-uptake inhibitor fluoxetine: case study using the European risk assessment framework, Integrated Environ. Assess. Manag. 6 (2010) 524-539, https://doi.org/10.1002/ieam.77.

[32] D.H. Pieper, W. Reineke, Engineering bacteria for bioremediation, Curr. Opin. Biotechnol. 11 (3) (2000) 262-270, https://doi.org/10.1016/S0958-1669(00) 00094-X.

[33] A.M. Mukred, A.A. Hamid, A. Hamzah, W.M.W. Yusoff, Development of three bacteria consortium for the bioremediation of crude petroleum-oil in contaminated water, Online J. Biol. Sci. 8 (4) (2008) 73-79, https://doi.org/ 10.3844/ojbsci.2008.73.79.

[34] P.L. McCarty, The development of anaerobic treatment and its future, Water Sci. Technol. 44 (8) (2001) 149-156.

[35] R. Reardon, J. Davel, D. Baune, S. McDonald, R. Appleton, R. Gillette, Wastewater treatment plants of the future: current trends shape future plans, Florida Water Res. J. 10 (2013) 8-14.

[36] P.E. Poh, D. Gouwanda, Y. Mohan, A.A. Gopalai, H.M. Tan, Optimization of wastewater anaerobic digestion using mechanistic and meta-heuristic methods: current limitations and future opportunities, Water Conserv. Sci. Eng. 1 (2016) 1-20, https://doi.org/10.1007/s41101-016-0001-3.

[37] Samcotech, What is anaerobic wastewater treatment?" and "How does anaerobic wastewater treatment work?. https://www.samcotech.com/ anaerobic-wastewater-treatment-how-it-works/. (Accessed 9 July 2019).

[38] M.C. Costa, J.C. Duarte, Bioremediation of acid mine drainage using acidic soil and organic wastes for promoting sulphate-reducing bacteria activity on a column reactor, Water Air Soil Pollut. 165 (1-4) (2005) 325-345, https:// doi.org/10.1007/s11270-005-6914-7.

[39] J.P. Da Costa, A.V. Girão, J.P. Lourenço, O.C. Monteiro, T. Trindade, M.C. Costa, Green synthesis of covellite nanocrystals using biologically generated sulfide: potential for bioremediation systems, J. Environ. Manag. 128 (2013) 226-232, https://doi.org/10.1016/j.jenvman.2013.05.034.

[40] G. Vitor, T.C. Palma, B. Vieira, M.C. Costa, Start-up, adjustment and long-term performance of a two-stage bioremediation process, treating real acid mine drainage, coupled with biosynthesis of $\mathrm{ZnS}$ nanoparticles and $\mathrm{ZnS} / \mathrm{TiO}_{2}$ nanocomposites, Miner. Eng. 75 (2015) 85-93, https://doi.org/10.1016/ j.mineng.2014.12.003.

[41] T.L. Palma, B. Vieira, J. Nunes, J.P. Lourenço, O.C. Monteiro, M.C. Costa, Photodegradation of chloramphenicol and paracetamol using $\mathrm{PbS} / \mathrm{TiO}_{2}$ nanocomposites produced by green synthesis, J. Iran. Chem. Soc. 17 (2020) 2013-2031, https://doi.org/10.1007/s13738-020-01906-1.

[42] F. Çeçen, G. Gül, Biodegradation of five pharmaceuticals: estimation by predictive Models and comparison with activated sludge data, Int. J. Environ. Sci. Technol. 18 (2021) 327-340, https://doi.org/10.1007/s13762-020-02820-y.
[43] T.L. Palma, M.N. Donaldben, M.C. Costa, J.D. Carlier, Putative role of Flavobacterium, Dokdonella and Methylophilus strains in paracetamol biodegradation, Water Air Soil Pollut. 229 (2018) 200, https://doi.org/10.1007/s11270018-3858-2.

[44] I. Langmuir, The adsorption of gases on plane surfaces of glass, mica and platinum, J. Am. Chem. Soc. 40 (9) (1918) 1361-1403, https://doi.org/ $10.1021 / \mathrm{ja0} 2242 \mathrm{a} 004$.

[45] H. Freundlich, Adsorption in solutions, Z. Phys. Chem. 57 (1906) 384-470.

[46] Y. Ho, G. McKay, Pseudo-second order model for sorption processes, Process, Biochem 34 (1999) 451-465, https://doi.org/10.1016/S0032-9592(98)001125.

[47] I. Michalak, K. Chojnacka, The new application of biosorption properties of Enteromorpha prolifera, Appl. Biochem. Biotechnol. 160 (2010) 1540-1556, https://doi.org/10.1007/s12010-009-8635-7.

[48] L.L. Barton, F.A. Tomei, Characteristics and Activities of Sulfate-Reducing Bacteria, Biotechnology Handbooks, vol. 8, Springer Science Business Media, University of New Mexico, Albuquerque, United States, 1995, pp. 1-32, https://doi.org/10.1007/978-1-4899-1582-5.

[49] J. Kleikemper, M.H. Schroth, W.V. Sigler, M. Schmucki, S.M. Bernasconi, J. Zeyer, Activity and diversity of Sulfate-Reducing Bacteria in a petroleum hydrocarbon-contaminated aquifer, Appl. Environ. Microbiol. 68 (4) (2002) 1516-1523, https://doi.org/10.1128/AEM.68.4.1516-1523.2002.

[50] B.D. Ensley, J.M. Suflita, Metabolism of environmental contaminants by mixed and pure cultures of sulfate-reducing bacteria, in: L.L. Barton (Ed.), Sulfatereducing Bacteria, Plenum Press, New York, N.Y, 1995, pp. 293-332.

[51] X. Zhang, L.Y. Young, Carboxylation as an initial reaction in the anaerobic metabolism of naphthalene and phenanthrene by sulfidogenic consortia, Appl. Environ. Microbiol. 63 (12) (1997) 4759-4764.

[52] G. Muyzer, A.J. Stams, The ecology and biotechnology of sulphate-reducing bacteria, Nat. Rev. Microbiol. 6 (6) (2008) 441-454, https://doi.org/10.1038/ nrmicro1892.

[53] J.R. Postgate, The Sulphate-Reducing Bacteria, University Press, Cambridge, 1984, p. 208, https://doi.org/10.1002/jobm.3620250311. Cambridge.

[54] J.C. Philp, K.J. Taylor, N. Christofi, Consequences of sulphate-reducing bacterial growth in a lab-simulated waste disposal regime, Experientia 47 (6) (1991) 553-559, https://doi.org/10.1007/BF01949877.

[55] C.D. Murphy, S. Quirke, O. Balogun, Degradation of fluorobiphenyl by Pseudomonas pseudoalcaligenes KF707, FEMS Microbiol. Lett. 286 (1) (2008) 45-49, https://doi.org/10.1111/j.1574-6968.2008.01243.x.

[56] J.-S. Seo, Y.-S. Keum, Q.X. Li, Bacterial degradation of aromatic compounds, Int. J. Environ. Res. Publ. Health 6 (1) (2009) 278-309, https://doi.org/10.3390/ ijerph6010278.

[57] V. Kumar, S.S. Maitra, Biodegradation of endocrine disruptor dibutyl phthalate (DBP) by a newly isolated Methylobacillus sp. V29b and the DBP degradation pathway, 3 Biotech 6 (2) (2016) 200, https://doi.org/10.1007/s13205-0160524-5.

[58] N.T. Dinh, N.H. Le, The performance of an anaerobic digester treating biosludge generated from a municipal wastewater treatment plant in a pilot scale, Chem. Eng. Trans. 78 (2020) 541-546.

[59] J. Wan, J. Gu, Q. Zhao, et al., COD capture: a feasible option towards energy self-sufficient domestic wastewater treatment, Sci. Rep. 6 (2016) 25054, https://doi.org/10.1038/srep25054.

[60] M. Alshabanat, G. Alsenani, R. Almufarij, Removal of crystal violet dye from aqueous solutions onto date palm fiber by adsorption technique, J. Chem. 2013 (2013) 1-6.

[61] K.V. Kumar, S. Gadipelli, B. Wood, K.A. Ramisetty, A.A. Stewart, C.A. Howard, D.J.L. Brett, F. Rodriguez-Reinoso, Characterization of the adsorption site energies and heterogeneous surfaces of porous materials, J. Mater. Chem. 7 (2019) 10104-10137, https://doi.org/10.1039/C9TA00287A.

[62] M. Suzuki, Adsorption Engineering, Kodansha-Elsevier, Tokyo, Japan, 1990, p. 146.

[63] K.M. Handley, D. Bartels, E.J. O’Loughlin, K.H. Williams, W.L. Trimble, K. Skinner, J.A. Gilbert, N. Desai, E.M. Glass, T. Paczian, A. Wilke, D. Antonopoulos, K.M. Kemner, F. Meyer, The complete genome sequence for putative $\mathrm{H}_{2}$ - and $\mathrm{S}$ oxidizer Candidatus Sulfuricurvum sp., assembled de novo from an aquifer-derived metagenome, Environ. Microbiol. 16 (11) (2014) 3443-3462, https://doi.org/10.1111/1462-2920.12453.

[64] J.J. Godon, E. Zumstein, P. Dabert, F. Habouzit, R. Moletta, Molecular microbial diversity of an anaerobic digestor as determined by small-subunit rDNA sequence analysis, Appl. Environ. Microbiol. 63 (7) (1997) 2802-2813.

[65] Z. Xie, Z. Wang, Q. Wang, C. Zhu, Z. Wu, An anaerobic dynamic membrane bioreactor (AnDMBR) for landfill leachate treatment: performance and microbial community identification, Bioresour. Technol. 161 (2014) 29-39, https://doi.org/10.1016/j.biortech.2014.03.014.

[66] L. Li, Q. Liu, Y.-X. Wang, H.-Q. Zhao, C.-S. He, H.-Y. Yang, L. Gong, Y. Mu, H.Q. Yu, Facilitated biological reduction of nitroaromatic compounds by reduced graphene oxide and the role of its surface characteristics, Sci. Rep. 21 (6) (2016) 30082, https://doi.org/10.1038/srep30082.

[67] B. Zhang, X. Xu, L. Zhu, Structure and function of the microbial consortia of activated sludge in typical municipal wastewater treatment plants in winter, Sci. Rep. 7 (2017), https://doi.org/10.1038/s41598-017-17743-x.

[68] C. Fischer-Romero, B.J. Tindall, F. Jüttner, Tolumonas auensis gen. nov., sp. nov., a toluene-producing bacterium from anoxic sediment of a freshwater lake, Int. J. Syst. Evol. Microbiol. 46 (1) (1996) 183-188, https://doi.org/10.1099/ 00207713-46-1-183. 
[69] X.C. Wang, J.M. Shen, Z.L. Chen, X. Zhao, H. Xu, Removal of pharmaceuticals from synthetic wastewater in an aerobic granular sludge membrane bioreactor and determination of the bioreactor microbial diversity, Appl. Microbiol. Biotechnol. 100 (18) (2016) 8213-8223, https://doi.org/10.1007/s00253-0167577-6.

[70] L. Giacomucci, F. Toja, P. Sanmartín, L. Toniolo, B. Prieto, F. Villa, F. Cappitelli, Degradation of nitrocellulose-based paint by Desulfovibrio desulfuricans ATCC13541, Biodegradation 23 (5) (2012) 705-716, https://doi.org/10.1007/ s10532-012-9546-9.

[71] G. Miralles, V. Grossi, M. Acquaviva, R. Duran, J.C. Bertrand, P. Cuny, Alkane biodegradation and dynamics of phylogenetic subgroups of sulfate-reducing bacteria in an anoxic coastal marine sediment artificially contaminated with oil, Chemosphere 68 (7) (2007) 1327-1334, https://doi.org/10.1016/ j.chemosphere.2007.01.033.

[72] F. Widdel, R. Rabus, Anaerobic biodegradation of saturated and aromatic hydrocarbons, Curr. Opin. Biotechnol. 12 (3) (2001) 259-276.

[73] M.L.G.C. Luijten, J. de Weert, H. Smidt, H.T.S. Boschker, W.M. de Vos, G. Schraa, A.J.M. Stams, Description of Sulfurospirillum halorespirans sp. nov., an anaerobic, tetrachloroethene-respiring bacterium, and transfer of Dehalospirillum multivorans to the genus Sulfurospirillum as Sulfurospirillum multivorans comb. nov, Int. J. Syst. Evol. Microbiol. 53 (3) (2003) 787-793, https://doi.org/ 10.1099/ijs.0.02417-0.

[74] D.E. Ross, C.W. Marshall, H.D. May, R.S. Norman, Comparative genomic analysis of Sulfurospirillum cavolei MES reconstructed from the metagenome of an electrosynthetic microbiome, PloS One 11 (3) (2016), e0151214, https:// doi.org/10.1371/journal.pone.0151214.

[75] M. Martins, S. Sanches, I.A.C. Pereira, Anaerobic biodegradation of pharmaceutical compounds: new insights into the pharmaceutical-degrading bacteria, J. Hazard Mater. 357 (2018) 289-297, https://doi.org/10.1016/ j.jhazmat.2018.06.001. 